\title{
Revisão
}

\section{Trabalho de consenso de força-tarefa da WFSBP\# sobre marcadores biológicos das demências: Contribuição da análise do LCR e do sangue para o diagnóstico precoce e diferencial das demências}

\author{
Consensus Paper of the WFSBP Task Force on Biological Markers of Dementia: \\ The role of CSF and blood analysis in the early and differential diagnosis of dementia \\ World J Biol Psychiatry. 2005;6(2):69-84. Review
}

\author{
Wiltfang $\mathrm{J}^{1,2}$, Lewczuk $\mathrm{P}^{1,2}$, Riederer $\mathrm{P}^{3}$, Grünblatt $\mathrm{E}^{3}$, Hock $\mathrm{C}^{4}$, Scheltens $\mathrm{P}^{5}$, Hampel $\mathrm{H}^{6}$, Vanderstichele $\mathrm{H}^{7}$, \\ Iqbal $\mathrm{K}^{8}$, Galasko $\mathrm{D}^{9}$, Lannfelt $\mathrm{L}^{10}$, Otto $\mathrm{M}^{11}$, Esselman $\mathrm{H}^{12}$, Henkel $\mathrm{AW}^{1}$, Kornhuber $\mathrm{J}^{12}$, Blennow $\mathrm{K}^{13}$ \\ ' Departamento de Psiquiatria e Psicoterapia, Universidade de Erlangen-Nuremberg, Erlangen, Alemanha. \\ ${ }^{2}$ Centro de Neuroproteômica Clínica, Erlangen, Alemanha. \\ ${ }_{3}^{3}$ Clínica de Psiquiatria e Psicoterapia, Departamento de Neuroquímica Clínica, Bayerische Julius-Maximilians-University Würzburg, Würzburg, Alemanha. \\ ${ }^{4}$ Divisão de Pesquisa em Psiquiatria, Universidade de Zurique, Zurique, Suiça. \\ ${ }^{5}$ Centro de Alzheimer/Departamento de Neurologia, Centro Médico da Universidade VU, Amsterdã, Holanda. \\ ${ }^{6}$ Departamento de Psiquiatria, Universidade Ludwig Maximilian, Munique, Alemanha. \\ ${ }^{7}$ Innogenetics, Ghent, Bélgica.
}

${ }^{8}$ Departamento de Neuroquímica, Departamento de Neuropatologia Clínica, Instituto do Estado de Nova lorque para Pesquisas Básicas em Incapacidades do Desenvolvimento, Nova lorque, NY, EUA.

${ }^{9}$ Departamento de Neurociências UCSD, La Jolla, CA, EUA.

${ }^{10}$ Departamento de Saúde Pública e de Ciências do Atendimento à Saúde/Geriatria, Universidade Uppsala, Uppsala, Suécia.

"Departamento de Neurologia, Universidade de Goettingen, Goettingen, Alemanha.

${ }^{12}$ Departamento de Psiquiatria e Psicoterapia, Universidade de Goettingen, Goettingen, Alemanha.

${ }^{13}$ Departamento de Neurociências Clínicas, Seção de Neurociência Experimental, Hospital da Universidade Sahlgrenska, Mölndal, Suécia.

Este manuscrito é uma tradução do trabalho publicado em 2005 realizada com a autorização dos respectivos autores.

Tradução: Dra. Vilma Ribeiro de Souza Varga

\section{Resumo}

O envelhecimento da população e o aumento da expectativa de vida resultam em um número cada vez maior de pacientes com demência. Os déficits cognitivos podem ser manifestações de uma doença curável do sistema nervoso central (por exemplo, neuroinflamação), como também de uma doença atualmente considerada irreversível, como a doença de Alzheimer (DA). Tendo em vista as novas abordagens terapêuticas para a DA, em que se avalia o potencial modificador da patogenia, torna-se necessário o estabelecimento de um diagnóstico confiável em vida. Embora a análise do líquido cefalorraquidiano (LCR) e do soro seja realização de rotina em doenças neuroinflamatórias, ainda necessita de padronização para ser usada como instrumento auxiliar no diagnóstico clínico da DA. Vários parâmetros relacionados à DA (tau total, formas fosforiladas de tau, peptídeos $\mathrm{A} \beta$, genótipo ApoE, p97 etc.) podem ser determinados no LCR. A combinação de alguns desses parâmetros proporciona sensibilidade e especificidade na faixa de $85 \%$ para o diagnóstico da DA, um valor usualmente atribuído a um bom instrumento de diagnóstico. Nesta revisão, são discutidas as publicações mais recentes sobre os marcadores neuroquímicos para o diagnóstico clínico das demências, com ênfase no diagnóstico precoce e diferencial da DA. Discutem-se brevemente as novas perspectivas oferecidas por tecnologias recentes, tais como a FCS (fluorescence correlation spectroscopy) e a técnica de espectrometria de massa pelo método SELDI-TOF (surface enhanced laser desorption/ionization time-of-flight mass spectrometry).

Wiltfang J, et al. / Rev Psiq Clín. 2009;36(1):1-16

Palavras-chave: Demência, doença de Alzheimer, neuroinflamação, líquido cefalorraquidiano. 


\begin{abstract}
Aging of population, and increasing life expectancy result in an increasing number of patients with dementia. This symptom can be a part of a completely curable disease of the central nervous system (e.g, neuroinflammation), or a disease currently considered irreversible (e.g, Alzheimer's disease, $\mathrm{AD}$ ). In the latter case, several potentially successful treatment approaches are being tested now, demanding reasonable standards of pre-mortem diagnosis. Cerebrospinal fluid and serum analysis (CSF/serum analysis), whereas routinely performed in neuroinflammatory diseases, still requires standardization to be used as an aid to the clinically based diagnosis of $\mathrm{AD}$. Several $\mathrm{AD}$-related CSF parameters (total tau, phosphorylated forms of tau, Aß peptides, ApoE genotype, p97, etc.) tested separately or in a combination provide sensitivity and specificity in the range of $85 \%$, the figure commonly expected from a good diagnostic tool. In this review, recently published reports regarding progress in neurochemical pre-mortem diagnosis of dementias are discussed with a focus on an early and differential diagnosis of AD. Novel perspectives offered by recently introduced technologies, e.g, fluorescence correlation spectroscopy (FCS) and surface enhanced laser desorption/ionization time-of-flight mass spectrometry (SELDI-TOF MS) are briefly discussed.
\end{abstract}

Wiltfang J, et al. / Rev Psiq Clín. 2009;36(1):1-16

Keywords: Dementia, Alzheimer's disease, neuroinflammation, cerebrospinal fluid.

\section{Introdução}

Em função do envelhecimento populacional e do aumento da expectativa de vida, os transtornos demenciantes irão se tornar um sério problema para os sistemas de atendimento à saúde. Em relação à doença de Alzheimer (DA), apesar do número cada vez maior de pacientes, poucos progressos foram feitos em direção a um melhor padrão para o diagnóstico em vida. Embora a sensibilidade do diagnóstico clínico seja relativamente alta (93\%), a especificidade pode ser mais baixa - 55\%, conforme relatado por um estudo clínico-patológico multicêntrico (Mayeux, 1998). Em mãos experientes, o diagnóstico clínico de DA pode ser preditivo da confirmação neuropatológica em $80 \%$ a $90 \%$ dos casos; contudo, o diagnóstico da DA em fases iniciais assim como o diagnóstico diferencial das apresentações demenciais incomuns continuam a ser tarefas difíceis em bases puramente clínicas.

A introdução das drogas antidemência, tais como os inibidores da acetilcolinesterase para o tratamento da DA, representou um potencial de benefício terapêutico considerável, ante uma doença até então considerada irreversível (recente revisão de Bullock, 2002; Knopman, 2001). Desse modo, a necessidade de se estabelecer um diagnóstico precoce e diferencial mais exato dos transtornos demenciantes torna-se ainda maior (1998). Biomarcadores da DA, baseados em métodos de neuroimagem e estudos do LCR, têm sido desenvolvidos como instrumentos de suporte ao diagnóstico clínico. O objetivo desta revisão, portanto, é resumir o que há atualmente de mais moderno no campo do diagnóstico neuroquímico das demências, enfocando em especial os biomarcadores de DA. Finalmente, novas perspectivas de pesquisa em biomarcadores para as demências, oferecidas por inovações técnicas de alta complexidade, tais como a espectroscopia de correlação e a espectrometria de massa, são discutidas resumidamente.
Como o líquido cefalorraquidiano (LCR) está em contato direto com o sistema nervoso central (SNC), espera-se que qualquer alteração da composição bioquímica do parênquima cerebral deva se refletir predominantemente no LCR. Uma recente revisão feita por Reiber (2001) apresenta critérios para se distinguir entre a difusão de proteínas derivadas do cérebro para o LCR e a difusão de proteínas do sangue para o LCR, possibilitando a identificação prioritária das proteínas de origem cerebral. A punção lombar é um procedimento fácil, com baixa incidência de complicações. Em um grande estudo de Andreasen et al. (2001), somente 4,1\% de todos os pacientes apresentaram cefaleia pós-punção. No estudo de Blennow et al. (1993), relatou-se uma proporção ainda menor (2\%). Desse modo, é razoável postular que a punção lombar seja um procedimento exequível no contexto clínico, moderadamente invasivo, e que a análise do LCR possa melhorar a abordagem diagnóstica atual, baseada no exame clínico e de neuroimagem.

\section{Demência como sintoma de doenças potencialmente reversíveis}

As síndromes demenciais podem ser decorrentes de várias doenças potencialmente tratáveis do SNC. Por essa razão, a Academia Americana de Neurologia recomenda a análise do LCR no diagnóstico diferencial dos casos de demência em que haja suspeita de: câncer metastático, infecção do SNC, sorologia positiva para sífilis, hidrocefalia, imunossupressão, vasculite do SNC e em todos os pacientes abaixo de 55 anos de idade (1994). Essas diretrizes foram recentemente confirmadas por Knopman et al. (2001). Além disso, a análise de rotina do LCR possibilita a investigação avançada das proteínas liquóricas, já que a análise de proteínas totais - tanto as derivadas do cérebro quanto as derivadas do sangue - depende da eficiência da barreira hematoencefálica, conforme indicado pelo quociente da concentração 
de albumina liquórica sobre a albumina sérica $\left(Q_{\mathrm{Alb}}\right)$ (Reiber e Peter, 2001).

As doenças inflamatórias do SNC, ao lado de inúmeras outras etiologias, formam um grupo de transtornos cognitivos reversíveis, na sua maioria caracterizados por distúrbios de memória. A análise do LCR é mandatória em todos os casos suspeitos.

A neuroborreliose é uma doença do SNC causada pela Borrelia burgdorferi, uma espiroqueta encontrada em carrapatos. Várias complicações neuropsiquiátricas têm sido observadas em associação a essa doença, incluindo quadros de demência, conforme descrito por Fallon e Nields (1994). A neuroborreliose deve ser considerada uma causa possível de sintomas neuropsiquiátricos, especialmente em áreas endêmicas. Com uma combinação de parâmetros analisados de rotina no LCR e no soro, o diagnóstico da neuroborreliose pode ser confirmado ou rejeitado com uma especificidade de 96\% e uma sensibilidade de 80\% (Tumani et al., 1995). O exame do LCR revela quebra de barreira hematoencefálica (com aumento do $Q_{\mathrm{Alb}}$ ), pleocitose mononuclear, aumento da fração $\operatorname{IgM}$ (síntese intratecal dominante ou isolada) e aumento dos índices de anticorpos específicos (Tumani et al., 1995; Reiber e Peter, 2001).

Na neurossífilis, outro exemplo de doença inflamatória do SNC que se apresenta com demência, observa-se função normal ou discreta disfunção da barreira hematoencefálica, acompanhada por síntese intratecal de IgM e de IgG (Reiber e Peter, 2001). As análises sorológicas (VDRL e TPHA) geralmente são positivas e confirmam o diagnóstico.

A infecção pelo vírus da imunodeficiência humana (HIV) pode afetar as funções cognitivas de várias maneiras. O envolvimento do SNC é uma complicação frequente da AIDS aparecendo em 30\% a 60\% dos pacientes (Luer et al., 1988). No estudo alemão de Poser et al. (1988), 11\% dos participantes com AIDS apresentavam demência, uma porcentagem um tanto mais baixa do que nos estudos feitos nos EUA (Navia e Price, 1987). Na encefalite pelo HIV, o comprometimento da memória e de outras funções cognitivas é muito mais frequente e anterior à instalação da demência relacionada à AIDS. Além da encefalite com comprometimento cognitivo, a infecção do SNC pelo HIV também favorece a ocorrência de infecções oportunistas. Estas incluem a neurotoxoplasmose, a infecção pelo citomegalovírus (CMV), a infecção pelo vírus do herpes simples (HSV), a neurotuberculose e outras. Como todas essas afecções são potencialmente tratáveis, seu diagnóstico diferencial deve sempre incluir análise do LCR. Os achados imunológicos (anticorpos específicos) combinados à análise genética (pela técnica de PCR) elevam a precisão do diagnóstico.

A doença de Whipple é uma infecção crônica causada pela bactéria Tropheryma whippelii. Entre os pacientes com acometimento do SNC, até $71 \%$ dos casos desenvolvem alterações cognitivas (Louis et al., 1996). Os sinais da infecção sistêmica incluem problemas gastrointesti- nais, perda de peso e artrite, e os sintomas da infecção do SNC incluem também paralisia supranuclear, alteração do nível de consciência e distúrbios dos movimentos (Louis, 2003). As alterações do LCR incluem pleocitose leve, com macrófagos PAS-positivos em aproximadamente $30 \%$ dos casos - as chamadas células de Sieracki. A técnica de PCR com oligonucleotídeos que reconhecem o DNA bacteriano pode aumentar substancialmente a sensibilidade do diagnóstico.

Déficits neuropsicológicos também ocorrem na evolução da esclerose múltipla (EM), incluindo o comprometimento da memória e síndromes demenciais (Rao, 1986; Rovaris e Filippi, 2000). Na análise do LCR, os pacientes com EM tipicamente apresentam contagem normal ou discreto aumento de células e sinais de quebra de barreira hematoliquórica. Observa-se também aumento das imunoglobulinas, com bandas oligoclonais de IgG e síntese local de IgG, IgM e, menos frequentemente, de IgA. Ocorre, com muita frequência, síntese intratecal de anticorpos específicos para vírus neurotrópicos (sarampo, rubéola e/ou varicelazoster), um fenômeno conhecido como reação MRZ (de sarampo [measles], rubéola e zoster). Clinicamente, a sensibilidade da reação MRZ e das bandas oligoclonais de IgG na EM é de $89 \%$ e $98 \%$ respectivamente, ou seja, comparável aos métodos por neuroimagem (Reiber et al., 1998); entretanto, a especificidade das bandas oligoclonais é muito mais baixa, já que elas são observadas em muitas afecções neuroinflamatórias. Atualmente, a focalização isoelétrica é considerada o método de escolha para detectar bandas oligoclonais no LCR/soro.

\section{Marcadores neuroquímicos da doença de Alzheimer}

A doença de Alzheimer (DA) é a principal causa de demência no idoso. Além disso, nos indivíduos mais idosos, a DA é uma importante causa de incapacitação e morte. Os marcadores neuropatológicos de DA são os depósitos extracelulares de $\beta$-amiloide (placas senis) e os emaranhados neurofibrilares (NFT, de neurofibrillary tangles) (revisão por Wiltfang et al., 2001b). Outros achados característicos são: perda neuronal com atrofia cerebral, distúrbios da neurotransmissão, bem como reação inflamatória local da glia.

Os requisitos para que um determinado teste seja aceito como parâmetro de diagnóstico para a DA foram propostos recentemente (1998). De maneira ideal, tal teste deve ser: capaz de detectar uma característica fundamental da patologia da DA, validado em casos neuropatologicamente confirmados, preciso e confiável, não invasivo, simples de realizar e barato. Além disso, a sensibilidade deve ser de aproximadamente $85 \%$ ou mais, e a especificidade deve ser igual ou superior a $75 \%$ - 85\% (1998). 
Proteína precursora do $\beta$-amiloide ( $\beta$-APP): metabolismo e impacto sobre o diagnóstico de DA

As placas de $\beta$-amiloide são compostas principalmente de peptídeos originados a partir da clivagem enzimática da proteína precursora do $\beta$-amiloide ( $\beta$-APP) (Kang et al., 1987). A $\beta$-APP é uma proteína transmembrana codificada na espécie humana por um gene localizado no cromossomo 21, e seu splicing alternativo resulta em pelo menos oito isoformas. A isoforma conhecida como $\beta$-APP 695 (ou seja, a que contém 695 resíduos de aminoácidos) expressa-se predominantemente no cérebro (Panegyres, 1997). Há controvérsias sobre o papel fisiológico da $\beta$-APP; entretanto, postula-se um envolvimento nas interações celulares e entre as células e a matriz extracelular. A $\beta$-APP é processada enzimaticamente pelas secretases $\alpha, \beta$ e $\gamma$, para liberar várias formas de peptídeos $\beta$-amiloide $(\mathrm{A} \beta)$. Esse processo é esquematicamente apresentado na Figura 1. A descoberta de peptídeos $\beta$-amiloide com diferentes constituições no domínio carboxiterminal (e, portanto, diferentes tamanhos) sugere a existência de diferentes pontos de clivagem pela $\gamma$-secretase. Se assim for, talvez possa ser sintetizado um inibidor específico capaz de impedir seletivamente a geração do A $\beta 1-42$, pelo bloqueio da clivagem na posição 42 , prevenindo assim a formação de placas de $\beta$-amiloide.

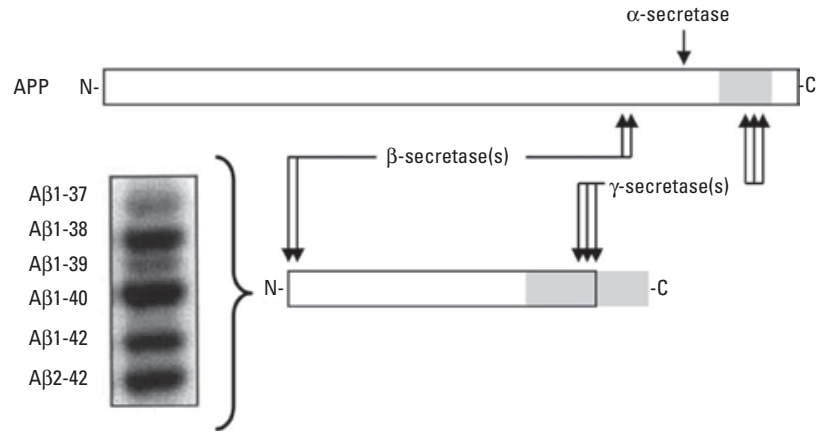

Figura 1. Clivagem da proteína precursora do amiloide (APP) pela $\beta$ e $\gamma$-secretases, levando à formação de pelo menos seis diferentes peptídeos. A posição "clássica" clivagem pela $\beta$-secretase é definida como a posição-1 dos peptídeos $A \beta$; entretanto, clivagens alternativas pela $\beta$-secretase levam à liberação de peptídeos truncados, começando na posição 2 ou 3 . As clivagens ulteriores pela $\gamma$-secretase levam à geração de $A \beta 1-40$ (quando ocorre no resíduo de isoleucina, localizado na posição 40) ou A $\beta 1-42$ (quando ocorre no resíduo de treonina, na posição 42). Recentemente, também foram encontrados peptídeos truncados de $A \beta$, terminando nas posições 37,38 e 39 do domínio C-terminal (Wiltfang et al., 2002). Isso pode indicar a presença de mais de uma atividade dessa enzima, o que pode ser útil na busca de um possível inibidor específico. 0 boxe cinza indica a posição do domínio transmembrana da APP.

Vários estudos, incluindo estes de nosso grupo, relatam diminuição da concentração do peptídeo A $\beta 1-42$ no LCR (Wiltfang et al., 2002; Lewczuk et al., 2004c), o mesmo sendo relatado em duas revisões da literatura (Blennow et al., 2001; Wiltfang et al., 2001b). Todavia, outro estudo sugere que o nível total de peptídeos $A \beta$ permanece inalterado (Motter et al., 1995). É ainda mais importante o fato de que os níveis de A $\beta 1-42$ no LCR parecem diminuir ao longo da evolução da doença, antes mesmo da deterioração grave das funções cognitivas dos pacientes (Riemenschneider et al., 2000). A Figura 2 exemplifica a diminuição dos níveis de A $\beta 1-42$ no LCR de paciente com DA, segundo o método de Western-blot. É preciso enfatizar que a concentração de $A \beta 1-42$ no LCR depende fortemente do tratamento pré-analítico das amostras (Wiltfang et al., 2002). Resultados obtidos com métodos envolvendo incubação com detergente ou calor (por exemplo, imunoprecipitação na presença de detergente ou desnaturação por SDS-calor) são até três vezes mais altos, em comparação aos resultados obtidos sem tal pré-tratamento (revisão de Wiltfang et $a l ., 2002)$. Esse achado indica a presença de uma fração de peptídeos $A \beta$ não acessível aos anticorpos, mais provavelmente por ligação a proteínas de transporte.

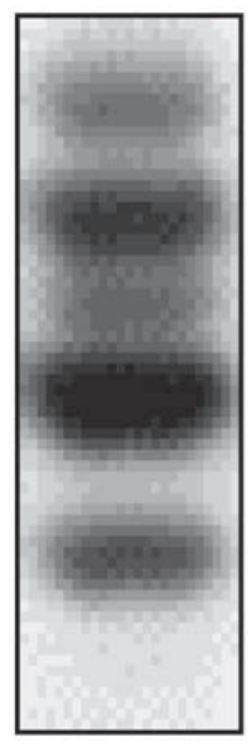

1

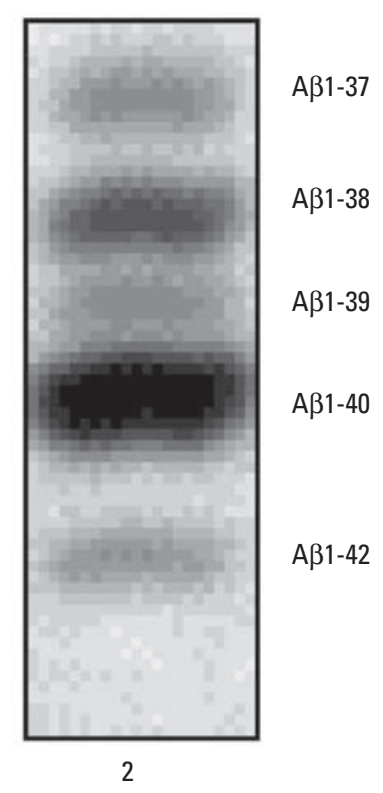

Figura 2. Espécies de $A \beta$ em imunoblot quantitativo por SDS-PAGE, mostrando diminuição de Aß1-42 no LCR de um paciente com DA (banda 2), em comparação a um controle sadio (banda 1). De acordo com Wiltfang et al. (2001a), com modificações.

Ainda não estão claros os mecanismos que levam à diminuição das concentrações de $A \beta 1-42$ no LCR de pacientes com DA. Alguns investigadores sugerem o acúmulo do peptídeo nas placas. Essa hipótese, contudo, não consegue explicar nossos resultados de diminuição da concentração do peptídeo no LCR de pacientes com doença de Creutzfeldt-Jakob (DCJ), que não desenvolvem placas de amiloide (Otto et al., 2000). De maneira semelhante, a diminuição dos níveis de A $\beta 1-42$ no LCR também foi registrada em casos de meningite bacteriana 
(Sjögren et al., 2001), uma doença que também pode causar déficits de memória crônicos, mas que não desencadeia a formação de placas de $\beta$-amiloide. De fato, os valores mais baixos de $A \beta 1-42$ encontrados no grande estudo multicêntrico de Hulstaert et al. (1999) foram observados em dois casos de panencefalite esclerosante subaguda e em um caso de meningite bacteriana. Como hipótese alternativa, é possível postular que a formação de complexos de ligação de $A \beta 1-42$ seria responsável pela diminuição da concentração do peptídeo no LCR (Wiltfang et al., 2002). Evidências recentes apontam para a ocorrência de tais complexos no LCR de pacientes com DA através da espectroscopia de correlação à fluorescência (Pitschke et al., 1998).

Os valores de sensibilidade e de especificidade de $A \beta 1-42$ que isoladamente distinguem os pacientes com DA dos controles idosos foram de $78 \%$ e $81 \%$, respectivamente (Hulstaert et al., 1999). Galasko et al. (1998) relataram valores semelhantes - de 78\% e 83\% para sensibilidade e especificidade respectivamente. Em nosso estudo (Lewczuk et al., 2004c), a utilização dos níveis de Aß42 no LCR isoladamente resultou em uma classificação correta de $87 \%$ dos participantes quando pacientes com demência não DA e indivíduos sem demência foram considerados como grupo-controle para DA. Blennow et al. (2001) analisaram dados de oito estudos com um número total de 562 pacientes com DA e 273 controles e relataram sensibilidade e especificidade médias de $85 \%$ e $84 \%$ respectivamente.

Mais recentemente, identificamos um peptídeo $A \beta$ truncado no domínio aminoterminal (A $\beta 2-42)$ no LCR de pacientes com DA (Wiltfang et al., 2001a), que corresponde ao segundo peptídeo $A \beta$ mais abundante no lobo frontal dos pacientes com DA, depois de $A \beta 1-42$. No LCR, o A $\beta 2-42$ está presente em cerca de $35 \%$ dos casos de DA. Estudos experimentais com camundongos knock-out mostraram que o $\mathrm{A} \beta 2$-42 é provavelmente produzido por uma clivagem alternativa da $\beta$-secretase. Esse achado tem importância fisiopatológica particular, pelo fato de que o A $\beta 2$-42 pode servir como primeiro ninho para a formação das placas de $\beta$-amiloide (Wiltfang et al., 2001a).

Outros peptídeos $\mathrm{A} \beta$ truncados no domínio carboxiterminal (A $\beta 1-37 / 38 / 39)$ foram identificados no LCR (Wiltfang et al., 2002) e no sangue humano (Lewczuk et al., 2004d), utilizando-se um sistema de eletroforese à base de ureia (Wiltfang et al., 1991). Esse padrão altamente conservado foi observado em todas as amostras de LCR investigadas até o momento, sendo a DA caracterizada por elevação (\%) da fração $A \beta 1-40$, redução da fração $A \beta 1-42 \%$ e elevação da fração $A \beta 1-38 \%$ em alguns casos (Wiltfang et al., 2002). A elevação da concentração do último peptídeo, observada também em alguns casos de doenças neuroinflamatórias crônicas, sustenta ainda mais o papel comumente aceito da inflamação no desenvolvimento da DA ( Eikelenboom et al., 2000; McGeer e McGeer, 2001).
Proteína tau e suas formas fosforiladas

As proteínas tau pertencem à família de proteínas associadas aos microtúbulos (do inglês, microtubuleassociated proteins - MAPs), encontradas nas células neuronais e não neuronais (revisão sobre o assunto por Buee et al., 2000). O gene humano da tau está localizado no braço longo do cromossomo 17. Seu splicing alternativo leva à formação de seis isoformas contendo de 352 a 441 aminoácidos. Estudos sobre o papel das proteínas tau têm revelado que sua principal função é promover a estabilidade da estrutura dos microtúbulos neuronais. As proteínas tau também promovem a nucleação, o crescimento e a agregação dos microtúbulos em feixes. O grau de fosforilação da proteína tau é um fator determinante da sua capacidade de interagir com os microtúbulos (revisão por Shahani e Brandt, 2002). Considera-se que o estado de fosforilação da tau varia durante o desenvolvimento do sistema nervoso, predominando as formas hiperfosforiladas da tau durante a fase de desenvolvimento fetal, que se segue por uma diminuição progressiva com a idade, mais provavelmente em decorrência da ativação de fosfatases (Mawal-Dewan et al., 1994; Rosner et al., 1995). Evidências cumulativas indicam que a tau também interage direta ou indiretamente com o citoesqueleto de actina, desempenhando um papel importante na regulação da forma e motilidade celular, bem como nas interações entre o microtúbulo e a membrana plasmática (para revisão, Shahani e Brandt, 2002). Conforme recentemente relatado pelo grupo de E. Mandelkow, a tau parece regular o tráfego intracelular de vesículas e inibir o transporte da proteína precursora do amiloide (APP) para as extensões neuronais, o que leva ao acúmulo de APP no corpo celular (Stamer $e t$ al., 2002). Estudos com culturas de células indicam que a tau também está envolvida no crescimento e na estabilização dos neuritos (Baas et al., 1991; Knops et al., 1991). Além disso, culturas primárias de neurônios de camundongos geneticamente modificados, onde o gene da tau foi deletado, mostram um retardo significativo da formação de projeções axonais e dendríticas (Dawson $e t$ $a l ., 2001)$. No entanto, outro grupo relatou um fenótipo completamente normal em camundongos knock-outs para o gene tau (Harada et al., 1994). Esses resultados aparentemente conflitantes foram explicados há pouco tempo pelo achado de que outras MAPs possivelmente compensem a falta do gene da tau (Takei et al., 2000). O papel de tau e de sua fosforilação pela enzima GSK-3 no transporte anterógrado e no crescimento dos neuritos foi recentemente mostrado por Tatebayashi et al. (2004).

A concentração de proteína tau tem sido extensivamente estudada como marcador inespecífico de destruição neuronal na DA. Por meio de uma metanálise, Sunderland et al. (2003) examinaram os achados de 17 artigos sobre A $\beta 42$ e 34 artigos sobre tau no LCR de pacientes com DA. Todos os estudos incluídos nessa 
metanálise relataram aumento de tau total no LCR na DA. Como alguns investigadores relataram um aumento da concentração de tau relacionado à idade em controles não demenciados (Buerger et al., 2003), os valores de referência para tau total devem ser aferidos pela idade dos sujeitos da amostra, como foi recentemente sugerido por Sjögren et al. (2001). Também se observa aumento das concentrações de tau total no LCR em distúrbios neuropsiquiátricos de outras etiologias (demências não DA), como na doença de Creutzfeldt-Jakob (DCJ) e nos acidentes vasculares cerebrais (AVCs) (Otto et al., 1997; Hesse et al., 2001). Todavia, dado o fato de que a DCJ e os AVCs agudos são facilmente distinguíveis clinicamente da DA, o valor diagnóstico desse marcador não deverá ser diminuído. Além disso, admite-se que os títulos de proteína tau no LCR possam ser usados para monitorar a eficácia dos tratamentos com neuroprotetores e outras drogas antidemência.

\section{Hiperfosforilação de tau como evento patológico}

Acredita-se que a fosforilação da tau em diferentes fosfoepitopos resulte em mudanças conformacionais da molécula, levando à diminuição da sua capacidade de se ligar aos microtúbulos e de promover montagem do esqueleto microtubular, aumentando assim a instabilidade dinâmica dos microtúbulos. A fosforilação do resíduo de serina 262 suprime parcialmente a capacidade de a tau ligar-se aos microtúbulos (Singh et al., 1996), enquanto a fosforilação dos resíduos treonina 231 e serina 235 reduz significativamente a ligação da tau aos microtúbulos (Sengupta et $a l ., 1998$ ). No cérebro de pacientes que sofrem de DA, moléculas hiperfosforiladas da proteína tau agregam-se para formar inclusões filamentosas intraneuronais, os emaranhados neurofibrilares, que correspondem a uma das características patológicas fundamentais da doença. O número de emaranhados neurofibrilares correlaciona-se estreitamente com a gravidade da demência (Alafuzoff et al., 1987; Braak e Braak, 1991; Arriagada et al., 1992). Depósitos intracelulares de tau hiperfosforilada são encontrados em outros distúrbios neurodegenerativos, conhecidos como tauopatias; entretanto, na DA, essas inclusões são descritas somente nos neurônios. Recentemente, foi sugerido que a fosforilação da tau na DA varie de acordo com o estágio evolutivo da demência, sendo os resíduos de aminoácidos 153, 262 e 231 modificados em uma etapa inicial da doença, e as posições 199, 202, 205, 396 e 404 hiperfosforiladas mais tardiamente (Augustinack et al., 2002). Essa evolução dos pontos de fosforilação da proteína tau corresponde à evolução morfológica dos emaranhados na DA. Simultaneamente, é possível detectar um aumento da concentração de formas fosforiladas de proteína tau no LCR dos pacientes com DA (Vanmechelen et al., 2000; Itoh et al., 2001; Buerger et al., 2002). Várias cinases são capazes de fosforilar a tau, como recentemente revisto por Buee et al. (2000), incluindo-se as proteína-quinases ativadas pelo estresse, as proteína-quinases ativadas por mitógenos, a glicogênio sintetase quinase-3 e outras.

\section{Tau fosforilada no LCS como biomarcador da doença de Alzheimer}

Embora se considere que o aumento da concentração de tau total no LCR reflita a degeneração inespecífica das células nervosas, a hiperfosforilação anormal de tau é uma característica que distingue a DA de outros processos neurodegenerativos (Iqbal et al., 1986), uma vez que as moléculas hiperfosforiladas de tau formam os emaranhados neurofibrilares (Grundke-Iqbal et al., 1986). Admite-se que a proteína tau possa ser fosforilada em 29 posições hipotéticas, sendo os resíduos de serina e treonina os predominantes. Recentemente, grupos independentes relataram o aumento das concentrações de tau fosforilada no LCR como forma de discriminar a DA de outros transtornos demenciantes. Nos estudos publicados até o momento, a sensibilidade e a especificidade dos níveis de tau fosforilada (em diferentes posições) para o diagnóstico da DA variaram de $44 \%$ a $94 \%$ e de $80 \%$ a $100 \%$ respectivamente (Blennow et al., 2001). Hu et al. (2002) demonstraram que a razão entre a fosfo-Tau396/404 e a tau total no LCR poderia discriminar DA de outras demências e doenças neurológicas com uma sensibilidade de $96 \%$ e uma especificidade de $94 \%$. Esses achados sugerem que a análise de tau fosforilada em serina-396/404 no LCR pode ser mais promissora que a fosforilação em outros epitopos, conforme os dados publicados até o momento. Também é preciso observar que, embora os processos que levam à hiperfosforilação da tau sejam predominantes na DA, a sua desfosforilação também acontece, e a proporção de moléculas fosforiladas para desfosforiladas da tau deve ser considerada dinamicamente. Além disso, o favorecimento de mecanismos que levam à desfosforilação de tau hiperfosforilada é uma possível (e promissora) abordagem terapêutica para a DA (Iqbal et al., 2002).

Em um estudo recente, encontramos aumento significativo das concentrações de fosfo-Tau181 no LCR de pacientes com DA, cujo diagnóstico clínico havia sido apoiado neuroquimicamente pela diminuição de A42 no LCR (Lewczuk et al., 2004a). Essa isoforma da tau parece ser particularmente interessante para o diagnóstico diferencial entre DA e doença cerebrovascular, já que a fosfo-Tau181 mantém-se inalterada, enquanto a tau total aumenta depois de um AVC agudo (Hesse et al., 2001). Isso pode sugerir que a fosfo-Tau181 não seja apenas marcador de perda neuronal simples. De maneira semelhante, Vanmechelen et al. (2001) encontraram níveis significantemente aumentados de fosfo-Tau181 no LCR de pacientes com DA, em comparação a todos os outros grupos estudados (DFT, DCL, doença de Parkinson, atrofia de múltiplos sistemas e paralisia supranuclear progressiva), à exceção da degeneração corticobasal. Parnetti et al. (2001) confirmaram que a fosfo-Tau181 
foi um biomarcador útil para distinguir DA da demência por corpos de Lewy. Além disso, concordando com os resultados de nosso estudo, Vanmechelen et al. (2001) e Nägga et al. (2002) verificaram forte correlação entre tau total e fosfo-Tau181, independentemente do grupo de diagnóstico. De maneira semelhante, foi relatado aumento das concentrações de fosfo-Tau181 no LCR de indivíduos com DA provável, em comparação com os controles (Nägga et al., 2002). Papassotiropoulos et al. (2003) verificaram aumento da concentração de fosfo-Tau181 no LCR associado a um polimorfismo de CYP46. O grupo de C. Hock relatou que esse gene está associado a um risco aumentado de DA esporádica de início tardio.

Com referência a outros sítios de fosforilação, Itoh $e t$ al. (2001) relataram, a partir de um estudo multicêntrico internacional, um aumento significante de fosfo-Tau199 em pacientes com DA, em comparação com todos os outros grupos não DA. A sensibilidade e a especificidade da fosfo-Tau199 no LCR para discriminar DA de outros grupos diagnósticos foram 85\% no nível de corte de 1,05 $\mathrm{fmol} / \mathrm{mL}$. A proteína tau fosforilada em treonina-231 (fosfo-Tau231) parece ajudar na diferenciação da DA de doenças relevantes, tais como a demência frontotemporal (DFT), a demência vascular (DV) e a demência por corpos de Lewy (DCL) (revisão de Blennow et al., 2001). Um estudo de seguimento revelou aumento da concentração de fosfo-Tau231 no LCR no início da doença, seguido de uma diminuição das concentrações desse marcador, mas não da tau total, num grupo de pacientes com DA não tratada. Isso pode sugerir um possível papel dessa isoforma para se rastrear a evolução natural da doença (Hampel et al., 2001). Traz interesse o fato de que a proteína tau fosforilada nas posições treonina-231 e serina-235 se mostrou aumentada nos pacientes com um comprometimento cognitivo leve (CCL) que desenvolveram DA durante o seguimento (Arai et al., 2000). Nesse estudo, uma avaliação simultânea de tau total e tau fosforilada distinguiu o grupo de pacientes com risco para desenvolverem DA daqueles que se queixavam de ter comprometimento da memória, mas não tinham perda de memória objetiva.

Em um estudo recentemente publicado, foram comparadas três diferentes formas de fosfo-tau com referência ao seu potencial para distinguir pacientes com formas distintas de demência, bem como controles não demenciados. O resultado deste estudo mostra desempenho global igual de fosfo-Tau181 e fosfo-Tau231, sendo o desempenho de fosfo-Tau199 um pouco pior. É interessante que a discriminação entre DA e demência por corpos de Lewy foi maximizada usando-se fosfo-Tau181, com uma sensibilidade de $94 \%$ e uma especificidade de 64\%; a fosfo-Tau231 maximizou a separação de grupos entre DA e demência frontotemporal com uma sensibilidade de $88 \%$ e uma especificidade de $92 \%$. Portanto, parece haver uma tendência (não significante) para que as proteínas tau fosforiladas ajam diferentemente na discriminação dos diferentes tipos de demência. (Hampel et al., 2004).

\section{Genótipo da apolipoproteína E (ApoE)}

A ApoE é uma proteína envolvida no transporte do colesterol. À parte da sua presença no plasma, a ApoE também é produzida por astrócitos no SNC para sustentar o crescimento e o reparo de neurônios. O gene da ApoE está localizado no cromossomo 19, sendo descritos três alelos: $\varepsilon 2$, $\varepsilon 3$ e $\varepsilon 4$. Existe um volume considerável de evidências que sustentam a associação entre o alelo ApoE $\varepsilon 4$ e a DA familial de início tardio (revisão por Mulder et al., 2000). Até $40 \%-50 \%$ dos pacientes com DA possuem o alelo $\varepsilon 4$, em comparação a $15 \%-25 \%$ dos controles (Strittmatter et al., 1993a). Relata-se que indivíduos homozigóticos para o alelo $\varepsilon 4$ têm um aumento de risco de 6 a 8 vezes de desenvolverem DA, em comparação ao risco de indivíduos heterozigóticos, que têm um aumento de risco de 3 a 4 vezes (Mulder et al., 2000). O alelo $\varepsilon 4$ foi identificado como um dos principais fatores de risco para a DA, independentemente de gênero, idade e origem étnica dos indivíduos (Farrer et al., 1997). Em um grande estudo feito nos Estados Unidos com 2.188 pacientes, a análise do alelo $\varepsilon 4$ mostrou leve sensibilidade e especificidade de $65 \%$ e $68 \%$ respectivamente (Mayeux et al., 1998). Desse modo, sugere-se que a genotipagem para o alelo da ApoE deva ficar reservada para os pacientes demenciados, e a presença de um ou dois alelos $\varepsilon 4$ da ApoE pode melhorar a especificidade do diagnóstico em pacientes que cumpram os critérios clínicos de DA. Ainda não estão claros quais são os mecanismos que regulam o aumento de risco de desenvolver DA em casos de portadores do alelo $\varepsilon 4$.

\section{Monoamina oxidase B no sangue como biomarcador de doença de Alzheimer}

Uma das enzimas envolvidas indiretamente no estresse oxidativo é a enzima que metaboliza as aminas, a monoamina oxidase B (MAO-B, E.C.: 1.4.3.4). Trata-se de uma enzima contendo flavina, localizada na membrana mitocondrial externa (Greenawalt e Schnaitman, 1970). É responsável pela desaminação oxidativa dos neurotransmissores (noradrenalina, dopamina e serotonina) e das aminas exógenas (por exemplo, a tiramina) (Weyler et al., 1990). Durante sua atividade catalítica, a MAO-B produz peróxido de hidrogênio, que é uma possível fonte de estresse oxidativo, que pode contribuir para a morte neuronal na DA, bem como em outras doenças neurodegenerativas (Riederer e Youdin, 1993). Vários estudos prévios relataram aumento da atividade da MAO-B no cérebro e em plaquetas de pacientes que sofrem de doenças neurodegenerativas, como as doenças de Alzheimer e de Parkinson (Adolfsson et al., 1980; Smith et al., 1982; Gottfries et al., 1983; Oreland e Gottfries, 1986; Alexopoulos et al., 1987; Danielczyk 
et al., 1988; Bonuccelli et al., 1990; Fischer et al., 1994; Zhou et al., 2001). A atividade da MAO-B (assim como da MAO-A) no cérebro de indivíduos com DA é específica por região cerebral: a atividade de MAO-B diminui no núcleo basal de Meynert e aumenta no polo temporal, enquanto o padrão de expressão é diferente na doença de Parkinson e na doença de Pick (Sparks et al., 1991). O aumento da MAO-B cerebral pode ser devido ao aumento da sua transcrição (Nakamura et al., 1990), observada predominantemente em astrócitos associados a placas, segundo estudos com cérebros de pacientes com DA neuropatologicamente confirmada e que apresentavam astrogliose (Jossan et al., 1991; Saura et al., 1994). No entanto, ainda é desconhecida a razão para o aumento de atividade da MAO-B nas plaquetas; isso pode estar relacionado à elevação transcricional da proteína MAO-B e/ou a alterações no meio celular, causando manipulação da atividade da enzima (Song et al., 2000; Damberg et al., 2001; Balciuniene et al., 2002). De acordo com outros estudos publicados (Oreland e Gottfries, 1986; Parnetti et al., 1994; Götz et al., 1998), mostramos, num estudo longitudinal com moradores de Viena na faixa dos 75 anos de idade, um aumento altamente significante da atividade de MAO-B plaquetária em pacientes com DA (Figura 3) (Fischer et al., 2002). Uma alteração da proporção do número de neurônios para o número de tecidos de sustentação nas áreas cerebrais em degeneração poderia explicar o aumento de atividade de MAO-B em pacientes com DA. No entanto, a ampliação da atividade da MAO-B nas plaquetas, que apenas expressam a forma $B$ da enzima, aponta para um fator adicional que, embora desconhecido, pode atuar na regulação transcricional (Ekblom et al., 1998) da quantidade de enzima e/ou na regulação cinética da atividade molecular de MAO-B nas plaquetas (Bongioanni et al., 1997; Song et al., 2000).

\section{Outros fatores possíveis}

Além dos biomarcadores “clássicos", ou seja, proteína(s) tau e suas formas fosforiladas, bem como os peptídeos $\mathrm{A} \beta$, vários outros candidatos a biomarcadores têm sido testados, como foi mostrado numa recente e extensa revisão (Frank et al., 2003).

As proteínas de filamento neural (do inglês, neuronal thread proteins - NTP) são uma família de moléculas expressas no SNC. Em um estudo post-mortem observou-se aumento significante da imunorreatividade às NTPs em cérebros de pacientes com DA (de la Monte e Wands, 1992). A partir desse achado, o exame do LCR para NTP revelou aumento da concentração dessas proteínas, que se correlacionou com a progressão da doença e a degeneração neuronal (de la Monte et al., 1992). Contudo, os parâmetros de sensibilidade e a especificidade dessa proteína como possível marcador de DA não foram determinados em um número suficientemente grande de pacientes.

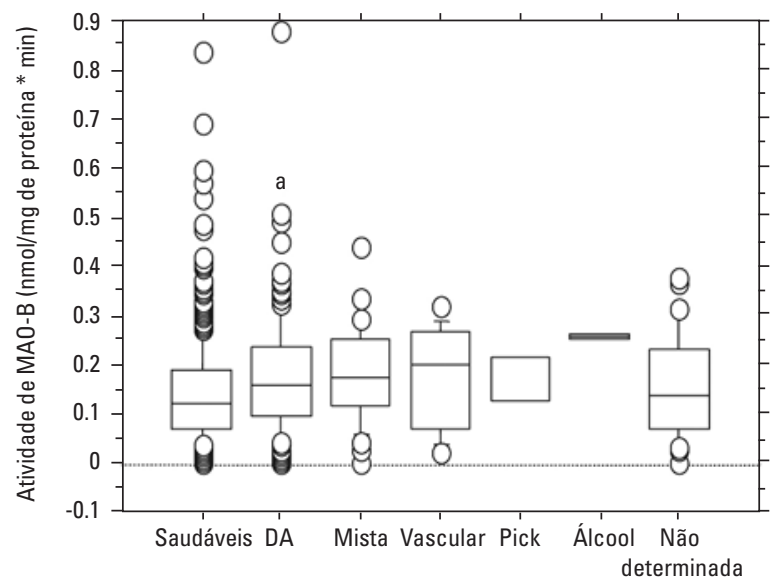

Figura 3. Nível de atividade da MAO-B em plaquetas no grupo VITA e centenário. Comparação entre diferentes grupos de diagnóstico de demência e controles. Idosos saudáveis, $n=473$, MMSE = 28,1 $\pm 0,06$; demência do tipo Alzheimer (DAT), $n=129$, MMSE = 13,6 0 0,81; demência mista, $n=29$, MMSE = 10,2 $\pm 1,49$; demência vascular, $n=11$, MMSE $=14,0 \pm 2,86$; doença de Pick, $n=3$, MMSE = 3,7 $\pm 3,66$; demência pelo álcool, $n=2, \mathrm{MMSE}=12,0 \pm$ 1,00; demência de causa indeterminada, $n=32$, MMSE $=20,0 \pm 2,02$. ANOVA e Fisher-PLSD: $P<0,005$; saudáveis vs. DAT.

A forma solúvel da p97, uma proteína de ligação ao ferro, parece aumentar no sangue de pacientes com DA. Em um primeiro estudo, todos os pacientes com DA tiveram concentração sanguínea elevada desse fator, não sendo observada sobreposição de valores entre pacientes e controles (Kennard et al., 1996). Recentemente, esse achado interessante foi confirmado por outros autores, embora usando um método analítico diferente (Ujiie et al., 2002). São necessários outros estudos para confirmar o potencial da p97 como marcador confiável para a DA. Um outro fator investigado no plasma, com resultados interessantes, é a homocisteína. Relatou-se que os níveis de homocisteína correlacionam-se com o risco de desenvolver DA, sendo que concentrações acima de $14 \mu \mathrm{mol} / \mathrm{L}$ estiveram associadas a um risco duas vezes maior de se desenvolver DA (Seshadri $e t$ al., 2002).

Dois grupos independentes de pesquisadores descreveram aumentos das concentrações do fator de crescimento transforming growth factor- $\beta 1$ na DA (Tarkowski et al., 2002; Zetterberg et al., 2004).

Como há cada vez mais evidências do envolvimento de lesão celular oxidativa e/ou nitrativa na patogênese da DA, diferentes fatores relacionados à peroxidação de lipídios têm sido testados como candidatos a marcadores da DA. Recentemente, Pratico et al. (2002) publicaram aumento dos níveis de isoprostanos (por exemplo, 8,12iso-iPF ${ }_{2 \alpha}$-VI) nos líquidos corpóreos de pacientes com DA. Esse achado foi ainda apoiado pelos níveis elevados desse fator nos líquidos corpóreos de camundongos transgênicos expressando a amiloidose própria da DA (Pratico et al., 2001). 


\section{Análise combinada de parâmetros do LCR}

Há muitos exemplos de doenças do SNC em que uma combinação de parâmetros do LCR melhora significativamente a precisão do diagnóstico. As doenças neuroinflamatórias, como a neuroborreliose (Tumani et $a l ., 1995)$ ou a esclerose múltipla (Reiber et al., 1998), são exemplos representativos. De maneira semelhante, foram publicados estudos mostrando aumento da sensibilidade e da especificidade da combinação de parâmetros do LCR no diagnóstico precoce e diferencial da doença de Alzheimer.

Em um estudo multicêntrico internacional, a análise combinada de A $\beta 1-42$ e da proteína tau mostrou uma sensibilidade de diagnóstico de $85 \%$ e uma especificidade de 58\% para distinguir DA dos tipos não Alzheimer de demência (Hulstaert et al., 1999). Nesse estudo, os níveis médios de sensibilidade e de especificidade de cada biomarcador isoladamente melhoraram de $74 \%$ a $79 \%$ para $86 \%$ quando ambos os marcadores foram considerados simultaneamente. Em nosso estudo (Lewczuk et al., 2004d), a análise combinada do $\mathrm{A} \beta 42$ e do $\mathrm{A} \beta 40$ através do quociente $A \beta 42 / A \beta 40$ proporcionou uma discriminação um pouco melhor entre pacientes com DA, portadores de demência não Alzheimer e controles sadios. Essa discriminação foi ainda melhor com a avaliação simultânea da concentração total de tau no LCR, e a combinação desses três parâmetros resultou em uma separação correta de $94 \%$ dos participantes do estudo. Em uma amostra de 105 pacientes com DA provável, Andreasen et al. (2001) reportaram uma sensibilidade de $94 \%$ para a análise combinada do $A \beta 1-42$ e da proteína tau total no LCR; já em uma amostra de 58 casos de DA possível, esses parâmetros proporcionaram uma sensibilidade de 88\% (Andreasen et al., 2001). A especificidade nesse estudo foi alta para diferenciar os casos de DA dos casos de transtornos psiquiátricos e de indivíduos não demenciados (100\% e $89 \%$ respectivamente); entretanto, as baixas concentrações de A $1-42$ encontradas em vários casos de DCL resultaram em uma especificidade mais baixa para discriminar essa doença. A especificidade mais baixa (48\%) foi identificada para a discriminação entre DA e demência vascular, provavelmente porque estes últimos pacientes tinham características patológicas concomitantes de DA. Um estudo de Kanai et al. (1998) apresentou estimativas semelhantes, de 71\% e 83\% para sensibilidade e especificidade, respectivamente, na análise simultânea de tau/Aß1-42.

Representando graficamente as concentrações de A $\beta 1-42$ versus tau, Motter et al. (1995) verificaram um valor preditivo positivo de $96 \%$ para o ulterior diagnóstico de DA nos indivíduos com tau alta/A 1-42 baixo e um valor preditivo negativo de $100 \%$ (isto é, de não apresentar DA) para os indivíduos com a relação inversa (tau baixa/A $1-42$ alto). Andreasen et al. (2001) também obtiveram estimativas semelhantes, com valores preditivos positivo e negativo de $90 \%$ e $95 \%$, respectivamente, numa prevalência de DA provável de 44\%. Para avaliar dados de análise simultânea de A $\beta 1-42$ e tau no LCR, Galasko et al. (1998) utilizaram o sistema de classificação binário, obtendo $85,2 \%$ de diagnósticos corretos, com sensibilidade e especificidade de $90 \%$ e $80 \%$ respectivamente. Em um estudo recentemente publicado, uma combinação de títulos baixos de A 342 e elevados de fosfo-Tau181 no LCR permitiu a discriminação entre pacientes com DA de início precoce e pacientes com degeneração lobar frontotemporal, com uma sensibilidade de $72 \%$ e especificidade de 93\% (Schoonenboom et al., 2004).

A análise combinada dos níveis de tau total (ou fosfotau) no LCR e do genótipo ApoE tem proporcionado resultados discrepantes. Arai et al. (1995) não relataram correlação entre tau total e o número de alelos $\varepsilon 4$ da ApoE, achado semelhante ao de Itoh et al. (2001) com referência à fosfo-tau199. Por outro lado, Golombowski et al. (1997) e Blomberg et al. (1996) verificaram que os pacientes com DA portadores do alelo $\varepsilon 4$ da ApoE apresentavam níveis mais altos de tau no LCR que aqueles sem ApoE- $\varepsilon$. Com referência à combinação do genótipo da ApoE e os títulos de A $\beta 1-42$ no LCR de pacientes com DA, níveis peptídicos mais altos foram identificados entre os pacientes não $\varepsilon 4$, níveis intermediários nos heterozigotos para $\varepsilon 4$, e mais baixos nos homozigotos para $\varepsilon 4$ (Galasko et al., 1998; Hulsaert et al., 1999; Riemenschneider et al., 2000). Como possível explicação para essa correlação, sugere-se uma alta afinidade de ligação de A $\beta 1-42$ à ApoE (Strittmatter $e t$ al., 1993b). Além disso, a análise combinada dos níveis liquóricos de tau e $\mathrm{A} \beta 1-42$ em pacientes portadores do alelo ع4 proporcionou aumento de $94 \%$ para $99 \%$ da sensibilidade para o diagnóstico de DA provável, e de $88 \%$ para 100\% para o diagnóstico de DA possível (Andreasen et al., 2001). Por outro lado, em um estudo com mais de 400 casos de DA, não foi identificado efeito do genótipo $\varepsilon 4$ da ApoE sobre os níveis de tau no LCR (Andreasen $e t$ $a l ., 1999)$. Essas observações levam à conclusão de que o genótipo ApoE deve ser levado em consideração na interpretação dos níveis de A $\beta 1-42$ e que a combinação de genotipagem de ApoE com outros parâmetros pode melhorar substancialmente os parâmetros de sensibilidade e especificidade do diagnóstico.

Recentemente, publicamos uma diminuição da fração de $\mathrm{A} \beta 1-42$ em relação a todos os peptídeos $\mathrm{A} \beta$ no LCR de pacientes com DA. Nesse estudo, todos os pacientes com DA (e nenhum dos controles) situaram-se abaixo da linha de discriminação de $8,5 \%$. Apresentando graficamente os resultados das proporções relativas de A $\beta 1-42$ contra A $\beta 1-38$, todos os casos de DA e nenhum dos controles foram encontrados na região compatível com a diminuição de $\mathrm{A} \beta 1-42$; entretanto, alguns casos de DA tinham aumento de A $\beta 1-38$ semelhante ao de indivíduos com doenças neuroinflamatórias crônicas (Wiltfang et al., 2002) (Figura 4). Essa observação aponta para a presença de reação (micro)inflamatória crônica no SNC de indivíduos com DA. Além disso, 
observou-se correlação negativa entre a gravidade da demência com a porcentagem (mas não com o valor absoluto) dos peptídeos de $\mathrm{A} \beta$ mais curtos nas suas extremidades carboxila.

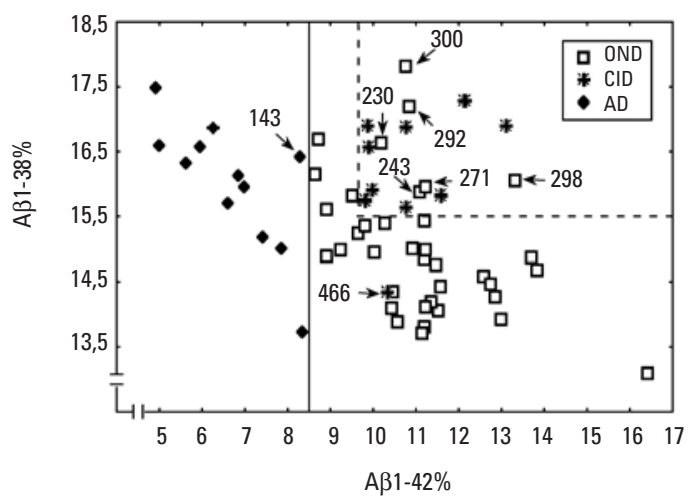

Figura 4. Gráfico da proporção da concentração relativa de $A \beta 1-38$ (eixo vertical, $A \beta 1-38 \%$ ) e da proporção da concentração relativa de $A \beta 1-42$ (eixo horizontal, $A \beta 1-42 \%$ ) no LCR. Foram investigados casos de doença de Alzheimer (AD), doenças neurológicas não demenciais (OND) e doenças neuroinflamatórias crônicas (CID). Com um valor discriminatório de 8,5\% para $A \beta 1-42 \%$, todos os casos de DA são separados de outros indivíduos, resultando numa sensibilidade de $100 \%$ e numa especificidade de $100 \%$. 0 aumento de $A \beta 1-38 \%$ acima de $15,5 \%$ observado em alguns casos de DA corresponde ao aumento de A $\beta 1-38 \%$ em CID e indica sinais de neuroinflamação nesses casos de DA. De acordo com Wiltfang et al. (2002), com modificações.

Um dos aspectos cruciais na análise dos parâmetros neuroquímicos nos transtornos demenciantes é a identificação de biomarcadores capazes de predizer o desenvolvimento de DA a partir do diagnóstico do comprometimento cognitivo leve (CCL). Espera-se que tal diagnóstico contribua para a instituição precoce do tratamento. De acordo com dados epidemiológicos de Petersen et al. (1999), aproximadamente $10 \%$ a $15 \%$ dos indivíduos com CCL desenvolvem DA em um ano. No seguimento de 44 pacientes com CCL que evoluíram para DA ao longo de um ano, Andreasen et al. (2003) demonstraram que a positividade dos biomarcadores em LCR contribui para um aumento da razão de risco para a conversão (tau total: 8,45 ; fosfo-tau: 7,49; $\mathrm{A} \beta 42$ : $8,2)$. Esses dados sugerem que esses biomarcadores já se encontram alterados nas fases iniciais da demência, e que esses parâmetros podem contribuir para a identificação dos indivíduos com CCL que evoluirão para DA. De maneira semelhante, Andreasen et al. (2001) mostraram que os níveis de tau já se encontravam elevados, e os de $\mathrm{A} \beta 42$, diminuídos, em pacientes com CCL na avaliação inicial.

Em um estudo publicado recentemente, uma combinação de três biomarcadores no LCR, a saber, tau total, fosfo-tau181 e A 342 , foi capaz de detectar casos de DA incipiente entre os pacientes com CCL, com uma sensi- bilidade de $68 \%$ ( $\left.\mathrm{IC}_{95 \%} 45 \%-86 \%\right)$ e uma especificidade de $97 \%\left(\mathrm{IC}_{95 \%} 83 \%-100 \%\right)$; portanto, os resultados do estudo sugerem a possibilidade de identificar, entre os pacientes com CCL, aqueles que futuramente desenvolverão DA, com importantes implicações sobre a indicação do tratamento (Zetterberg et al., 2003).

Uma limitação na interpretação dos resultados dos diferentes estudos com biomarcadores no LCR é a falta de padronização dos métodos laboratoriais. Os níveis de marcadores do LCR variam entre estudos realizados em diferentes centros, ainda que utilizando o mesmo método (ELISA), e também entre estudos baseados em métodos diferentes. Dessa forma, a padronização dos procedimentos será um pré-requisito para futuros estudos. Como parte de um projeto visando à definição de parâmetros de controle externo, alíquotas de LCR com diferentes níveis de tau e de $\mathrm{A} \beta$ serão disponibilizadas. Isso fornecerá um instrumento para padronização dos métodos laboratoriais e, desse modo, uma oportunidade para as comparações diretas dos resultados de diferentes centros acadêmicos.

Vários fatores de confusão pré-analíticos e biológicos podem influenciar os resultados das análises do LCR. Entre eles, os gradientes de concentração da proteína ao longo da medula espinal, a influência de hemorragia no ato da punção lombar, a presença da proteína no plasma e sua passagem pela barreira hematoencefálica e/ou hematoliquórica, e a degradação ou perda da proteína in vitro depois da coleta da LCR. Para as determinações da tau e $\mathrm{A} \beta$ no LCR, o único fator de confusão pré-analítico é que todas as proteínas têm uma tendência para aderir às paredes dos tubos de ensaio feitos de vidro e plástico duro, resultando em níveis erroneamente baixos (Andreasen et al., 1999). Portanto, é importante colher o LCR em tubos de ensaio não absorventes feitos de polipropileno. $\mathrm{O}$ armazenamento de LCR por até três dias não influencia os níveis dessas proteínas. Desse modo, as amostras de LCR podem ser enviadas ao laboratório em temperatura ambiente, depois do que todas as amostras de LCR devem ser congeladas antes da determinação das concentrações dos biomarcadores.

As características intrínsecas dos anticorpos usados nos imunoensaios para quantificação das proteínas de interesse são outro ponto a considerar. Diferentes anticorpos reconhecem diferentes isoformas das proteínas ou suas alterações conformacionais. As características dos anticorpos monoclonais HT7, BT2 e AT120, contra tau, foram descritas com detalhes por Vanmechelen et al. (2000). Dados não publicados de nosso grupo mostraram que, quando combinado ao HT7, o anticorpo monoclonal AT120 (um anticorpo que reconhece a proteína tau independentemente do seu estado de fosforilação) é melhor que o anticorpo BT2 (que reconhece o resíduo não fosforilado da tau em serina199) para diferenciar casos de DA dos controles. A quantificação do peptídeo $\beta$-amiloide baseia-se na ligação de anticorpos aos seus domínios C-terminal e N-terminal. 
Conquanto o anticorpo 3D6 exija um grupo $\mathrm{NH}_{2}$ livre no domínio N-terminal do peptídeo $\beta$-amiloide, outros anticorpos (por exemplo, 6E10, 4G8, WO2) também reconhecem espécies de $\beta$-amiloide truncadas no segmento N-terminal.

Perspectivas: Novas técnicas para a pesquisa de biomarcadores para a DA (FCS - fluorescence correlation spectroscopy, MS - espectrometria de massa, DIGE ${ }^{\mathrm{TM}}$ e multiplexing)

Uma nova abordagem para analisar a tendência dos peptídeos $\mathrm{A} \beta$ de formarem grandes agregados é sua detecção e quantificação no LCR pelo método denominado fluorescence correlation spectroscopy (FCS) (Eigen e Rigler, 1994). Esses agregados são o principal componente das placas de amiloide associadas à DA (Beyreuther et al., 1993), e o potencial de formar agregados é determinado primariamente pela estrutura secundária dos peptídeos $\mathrm{A} \beta$, e não por sua estrutura primária (sequência de aminoácidos) (Selkoe, 1994). Os peptídeos $\mathrm{A} \beta$ solúveis que apresentam uma grande proporção de estruturas betapregueadas formam agregados fibrilares insolúveis, em um processo descrito como "polimerização semeada” (Harper e Lansbury, 1997).

A FCS detecta a fluorescência de moléculas marcadas que entram num pequeno volume confocal iluminado de menos de $1 \mathrm{fl}$ por uma difusão aleatória. Como o coeficiente de difusão das moléculas depende de seu tamanho, é possível distinguir entre grandes agregados de moléculas e monômeros diminutos. Grandes agregados isolados produzem flashes fluorescentes intensos quando atravessam o volume confocal, tornando-os mais fáceis de detectar contra o fundo muito mais baixo dos monômeros. O potencial do FCS para o diagnóstico da DA foi demonstrado pela primeira vez há cinco anos (Pitschke et al., 1998). Peptídeos sintéticos A $\beta 1-42$ marcados com um agente fluorescente foram misturados ao LCR de pacientes com DA, de pacientes com demência não-Alzheimer e de controles saudáveis. Na presença de zinco, essas sondas precipitam-se nos agregados de amiloide preexistentes no LCR (Brown et al., 1997). Todos os pacientes com DA tiveram uma concentração significantemente mais alta de agregados grandes do que os controles e os pacientes com demência não Alzheimer. Esse estudo demonstrou que a técnica da FCS é instrumento extremamente sensível para uso futuro no diagnóstico pré-clínico e diferencial de DA. Possui o potencial para detecção sensível e seletiva de agregados nocivos de amiloide no plasma, sustentando ainda mais o diagnóstico baseado em marcadores mensurados no LCR.
A espectrometria de massa pelo método SELDITOF-MS (do inglês, surface-enhanced laser desorption/ ionization time-of-flight mass spectrometry) é atualmente aplicada em muitos campos de ciências biológicas e médicas, como foi extensamente revisado por Merchant e Weinberger (2000). Brevemente, amostras biológicas de diversas naturezas (por exemplo, plasma, liquor, sobrenadantes de culturas celulares etc.) são aplicadas à superfície de chips de proteínas ("ProteinChips") que simulam interações cromatográficas (por exemplo, trocadores de cátions/ânions, superfícies de interações hidrófobas ou de afinidade metálicas etc.) e, depois de etapas de lavagem, somente aquelas moléculas retidas na superfície são submetidas à análise futura. A perspectiva direta dessa tecnologia são os chips de imunoafinidade, em que anticorpos específicos são acoplados por ligação covalente à superfície do chip a fim de capturar antígenos de interesse. Essas moléculas são então submetidas à dessorção e à ionização com um disparo de laser, e o "tempo de voo" (time of flight) das moléculas no vácuo do espectrômetro de massa se correlaciona com a massa molecular dos íons. Aplicando-se os padrões de massa, a massa molecular dos peptídeos/proteínas analisadas pode ser determinada com margem de erro inferior a 0,05\%, ou seja, cerca de 2-3 Da na faixa de massa molecular dos peptídeos. Os polipeptídeos de interesse podem ainda ser caracterizados por sequenciamento de fase gasosa e pelo mapeamento deles pela tecnologia de espectroscopia de massa (por exemplo, LC-MS/MS1). $\mathrm{O}$ método SELDI-TOF-MS mostrou-se recentemente adequado para analisar peptídeos $\beta$-amiloide em sobrenadantes de culturas de células HEK 293 transfectadas (Frears et al., 1999), e fomos recentemente o primeiro grupo a analisar e comparar os padrões de peptídeos $\mathrm{A} \beta$ no LCR humano e no tecido cerebral post-mortem em pacientes com DA e em controles não demenciados (Lewczuk et al., 2003, 2004b) ${ }^{2}$.

Outra técnica com grande potencial é a eletroforese de fluorescência diferencial em gel bidimensional (DI$\mathrm{GE}^{\mathrm{TM}}$ - do inglês, two dimensional fluorescence difference gel electrophoresis), que oferece a oportunidade avançada de estudar alterações da expressão de proteínas em materiais biológicos (Karp et al., 2004). Em resumo, até três amostras simultâneas podem ser separadas por eletroforese no mesmo gel, sendo então escaneadas por um aparelho de processamento de imagem a laser com três feixes fluorescentes (Typhoon scanner). A etapa crucial do procedimento é marcar as proteínas com sondas fluorescentes (CyDye), o que permite quantificar precisamente diferenças de padrões de expressão proteica (coeficientes de variações menores que 20\% em até 3.000 spots individuais) usando um software sofisticado (DeCyder). Como amostras de diferentes fontes (por exemplo, de pacientes e controles) correm

1 N.T.: Cromatografia líquida de alta eficiência acoplada à espectrometria de massas em série.

2 N.T.: Método para separação de partículas de acordo com o tempo necessário para que elas atravessem um tubo com um certo comprimento. 
simultaneamente num único gel, a imprecisão do método afeta proteínas semelhantes de um modo similar, ou seja; são compensados os erros metodológicos. A sensibilidade de detecção para proteínas está na ordem de nanogramas. Apesar da marcação fluorescente, a proteína de interesse ainda pode ser caracterizada por sequenciamento de fase gasosa e mapeamento peptídico. As proteínas altamente expressas são inicialmente depletadas das amostras de LCR dos pacientes com distúrbios neurodegenerativos e controles por colunas de imunoafinidade. Após a retirada de sais e concentração, as amostras são estudadas pelo método DIGE com o uso de gradientes de $\mathrm{pH}$ imobilizados (IPG, gradiente não linear de 3-10) na primeira dimensão e géis de SDS-PAGE (step gradient) na segunda dimensão (faixa de massas moleculares: 600.000-5.000).

Os métodos de multiplexação visam à análise combinada de vários marcadores do LCR, o que será provavelmente um recurso necessário para melhorar o desempenho diagnóstico das novas tecnologias. Um desses métodos é a tecnologia xMap à base de micro-esferas (Luminex, Austin, TX, EUA), que é um método pautado na citometria de fluxo baseado em anticorpos acoplados a microesferas fluorescentes, espectralmente específicas (Vignali, 2000). Um outro anticorpo relator fluorescente liga-se à proteína capturada nas microesferas. Cada microesfera é identificada espectralmente, e a quantificação baseia-se na intensidade do sinal do relator. Em comparação aos métodos ELISA convencionais, essa tecnologia multiplex permite quantificação simultânea de até 100 proteínas em um pequeno volume de amostra e proporciona reprodutibilidade mais alta que aquela obtida por múltiplas determinações pelo método ELISA. Temos usado a tecnologia xMap para elaborar provas multiplex para quantificação simultânea de várias isoformas de $\mathrm{A} \beta$ e de tau. Dados preliminares mostram desempenho diagnóstico igual ou melhor, em comparação ao método ELISA.

\section{Conclusões}

O número cada vez maior de pacientes com demência exige melhora dos padrões de diagnóstico ainda em vida. Evidências cumulativas, resumidas neste trabalho, apoiam a análise do LCR como parte da investigação diagnóstica para a demência. Quando é forte a suspeita clínica de uma doença infecciosa ou inflamatória, ou na demência subaguda, a análise de rotina do LCR combinada aos testes para causas infecciosas pode produzir um diagnóstico específico de condições muitas vezes tratáveis. A análise do LCR no diagnóstico diferencial das demências é também sustentada pela baixa incidência de complicações pós-punção, como demonstrado em grupos relevantes de pacientes (Blennow et al., 1993; Andreasen et al., 2001). A análise comparativa dos parâmetros bioquímicos no LCR/soro deve ser realizada, de acordo com o conceito (baseado em pressupostos teóricos e confirmado na prática) da difusão proteica relacionada ao fluxo do LCR (Reiber e Peter, 2001). A análise da razão $\mathrm{LCR} /$ soro pode fornecer informações úteis nos casos de afecções ainda consideradas intratáveis nos dias de hoje. Um diagnóstico precoce e definitivo pode fornecer uma janela de tempo aceitável para iniciar o tratamento durante um período em que o paciente tenha comprometimento relativamente leve e tenha mais possibilidades de se beneficiar da terapêutica. À medida que é testado um tratamento mais definitivo, torna-se obrigatório o diagnóstico muito precoce da DA. A análise simultânea de dois ou mais fatores no LCR pode melhorar significativamente a precisão do diagnóstico da DA. São necessários mais estudos para confirmar a sensibilidade e a especificidade dos marcadores, incluindo estudos em pacientes que tiveram confirmação neuropatológica do diagnóstico. Com a introdução de novas técnicas de alta sensibilidade, como a FCS ou a espectrometria de massa, espera-se maior avanço no diagnóstico precoce da doença de Alzheimer.

\section{Declaração de interesse}

Este estudo faz parte da Rede Alemã de Pesquisas sobre Demência e recebeu recursos financeiros do Ministério Federal Alemão de Educação e Pesquisa (concessão O1 GI 0102).

\section{Referências}

Adolfsson R, Gottfries CG, Oreland L, Wiberg A, Winblad B. 1980. Increased activity of brain and platelet monoamine oxidase in dementia of Alzheimer type. Life Sci 27:1029/1034.

Alafuzoff I, Iqbal K, Friden H, Adolfsson R, Winblad B. 1987. Histopathological criteria for progressive dementia disorders: Clinical-pathological correlation and classification by multivariate data analysis. Acta Neuropathol (Berlin) 74:209/225.

Alexopoulos GS, Young RC, Lieberman KW, Shamoian CA. 1987. Platelet MAO activity in geriatric patients with depression and dementia. Am J Psychiatry 144:1480/1483.

Andreasen N, Minthon L, Clarberg A, Davidsson P, Gottfries J, Vanmechelen E, Vanderstichele H, Winblad B, Blennow K. 1999. Sensitivity, specificity, and stability of CSF-tau in AD in a community-based patient sample. Neurology 53:1488/1494.

Andreasen N, Minthon L, Davidsson P, Vanmechelen E, Vanderstichele H, Winblad B, Blennow K. 2001. Evaluation of CSFtau and CSF-Ab42 as diagnostic markers for Alzheimer disease in clinical practice. Arch Neurol 58:373/379.

Andreasen N, Vanmechelen E, Vanderstichele H, Davidsson P, Blennow K. 2003. Cerebrospinal fluid levels of total-tau, phospho-tau and $A$ beta 42 predicts development of Alzheimer's disease in patients with mild cognitive impairment. Acta Neurol Scand Suppl 179:47/51.

Arai H, Terajima M, Miura M, Higuchi S, Muramatsu T, Machida N, Seiki H, Takase S, Clark CM, Lee VM et al. 1995. Tau in cerebrospinal fluid: a potential diagnostic marker in Alzheimer's disease. Ann Neurol 38:649/652.

Arai H, Ishiguro K, Ohno H, Moriyama M, Itoh N, Okamura N, Matsui T, Morikawa Y, Horikawa E, Kohno H, Sasaki H, Imahori K. 2000. CSF phosphorylated tau protein and mild cognitive impairment: A prospective study. Exp Neurol 166:201/203.

Arriagada PV, Growdon JH, Hedley-Whyte ET, Hyman BT. 1992. Neurofibrillary tangles but not senile plaques parallel duration and severity of Alzheimer's disease. Neurology 42:631/639. 
Augustinack JC, Schneider A, Mandelkow EM, Hyman BT. 2002. Specific tau phosphorylation sites correlate with severity of neuronal cytopathology in Alzheimer's disease. Acta Neuropathol (Berlin) 103:26/35.

Baas PW, Pienkowski TP, Kosik KS. 1991. Processes induced by tau expression in Sf9 cells have an axon-like microtubule organization. $J$ Cell Biol 115:1333/1344.

Balciuniene J, Emilsson L, Oreland L, Pettersson U, Jazin E. 2002. Investigation of the functional effect of monoamine oxidase polymorphisms in human brain. Hum Genet 110:1/7.

Beyreuther K, Pollwein P, Multhaup G, Monning U, Konig G, Dyrks T, Schubert W, Masters CL. 1993. Regulation and expression of the Alzheimer's beta/ A4 amyloid protein precursor in health, disease, and Down's syndrome. Ann NYAcad Sci 695:91/102.

Blennow K, Wallin A, Hager 0. 1993. Low frequency of postlumbar puncture headache in demented patients. Acta Neurol Scand 88:221/223.

Blennow K, Vanmechelen E, Hampel H. 2001. CSF total tau, Ab42 and phosphorylated tau protein as biomarkers for Alzheimer's disease. Mol Neurobiol 24:87/97.

Blomberg M, Jensen M, Basun H, Lannfelt L, Wahlund LO. 1996. Increasing cerebrospinal fluid tau levels in a subgroup of Alzheimer patients with apolipoprotein E allele epsilon 4 during 14 months follow-up. Neurosci Lett 214:163/166.

Bongioanni P, Gemignani F, Boccardi B, Borgna M, Rossi B. 1997. Platelet monoamine oxidase molecular activity in demented patients. Ital $\mathrm{J}$ Neurol Sci 18:151/156

Bonuccelli U, Piccini P, Marazziti D, Cassano GB, Muratorio A. 1990. Increased platelet $3 \mathrm{H}$-imipramine binding and monoamine oxidase B activity in Alzheimer's disease. J Neural Transm Park Dis Dement Sect 2:139/147.

Braak H, Braak E. 1991. Neuropathological stageing of Alzheimer-related changes. Acta Neuropathol (Berlin) 82:239/259.

Brown AM, Tummolo DM, Rhodes KJ, Hofmann JR, Jacobsen JS, Sonnenberg-Reines J. 1997. Selective aggregation of endogenous beta-amyloid peptide and soluble amyloid precursor protein in cerebrospinal fluid by zinc. J Neurochem 69:1204/1212.

Buee L, Bussiere T, Buee-Scherrer V, Delacourte A, Hof PR. 2000. Tau protein isoforms, phosphorylation and role in neurodegenerative disorders. Brain Res Brain Res Rev 33:95/130.

Buerger K, Zinkowski R, Teipel S.J, Tapiola T, Arai H, Blennow K, Andreasen $\mathrm{N}$, Hofmann-Kiefer K, DeBernardis J, Kerkman D, McCulloch C, Kohnken R, Padberg F, Pirttila“'T, Schapiro MB, Rapoport SI, Mo“ Iler HJ, Davies P, Hampel H. 2002. Differential diagnosis of Alzheimer disease with cerebrospinal fluid levels of tau protein phosphorylated at threonine 231. Arch Neurol 59:1267/1272.

Buerger K, Zinkowski R, Teipel SJ, Arai H, DeBernardis J, Kerkman D, McCulloch C, Padberg F, Faltraco F, Goernitz A, Tapiola T, Rapoport SI, Pirttila T, Moller HJ, Hampel H. 2003. Differentiation of geriatric major depression from Alzheimer's disease with CSF tau protein phosphorylated at threonine 231. Am J Psychiatry 160:376/379.

Bullock R. 2002. New drugs for Alzheimer's disease and other dementias. Br J Psychiatry 180:135/139.

Damberg M, Garpenstrand H, Hallman J, Oreland L. 2001. Genetic mechanisms of behavior: Don't forget about the transcription factors. Mol Psychiatry 6:503/510.

Danielczyk W, Streifler M, Konradi C, Riederer P, Moll G. 1988. Platelet MAO-B activity and the psychopathology of Parkinson's disease, senile dementia and multi-infarct dementia. Acta Psychiatr Scand 78:730/736.

Dawson HN, Ferreira A, Eyster M.V, Ghoshal N, Binder LI, Vitek MP. 2001. Inhibition of neuronal maturation in primary hippocampal neurons from tau deficient mice. J Cell Sci 114:1179/1187.

de la Monte SM, Volicer L, Hauser SL, Wands JR. 1992. Increased levels of neuronal thread protein in cerebrospinal fluid of patients with Alzheimer's disease. Ann Neurol 32:733/742.

de la Monte SM, Wands JR. 1992. Neuronal thread protein overexpression in brains with Alzheimer's disease lesions. J Neurol Sci 113:152/164.

Eigen M, Rigler R. 1994. Sorting single molecules: application to diagnostics and evolutionary biotechnology. Proc Natl Acad Sci USA 91:5740/5747.
Eikelenboom P, Rozemuller AJ, Hoozemans JJ, Veerhuis R, van Gool WA. 2000. Neuroinflammation and Alzheimer disease: clinical and therapeutic implications. Alzheimer Dis Assoc Disord 14:S54/61.

Ekblom J, Garpenstrand H, Damberg M, Chen K, Shih JC, Oreland L. 1998. Transcription factor binding to the core promoter of the human monoamine oxidase B gene in the cerebral cortex and in blood cells. Neurosci Lett 258:101/104.

Fallon BA, Nields JA. 1994. Lyme disease: A neuropsychiatric illness. Am J Psychiatry 151:1571/1583

Farrer LA, Cupples LA, Haines JL, Hyman B, Kukull WA, Mayeux R, Myers RH, Pericak-Vance MA, Risch N, van Duijn CM. 1997. Effects of age, sex, and ethnicity on the association between apolipoprotein $\mathrm{E}$ genotype and Alzheimer disease. A meta-analysis. APOE and Alzheimer Disease Meta Analysis Consortium. J Am Med Assoc 278:1349/1356.

Fischer P, Gotz ME, Ellinger B, Streifler M, Riederer P, Danielczyk W. 1994. Platelet monoamine oxidase B activity and vitamin B12 in dementia. Biol Psychiatry 35:772/774.

Fischer P, Jungwirth S, Krampla W, Weissgram S, Kirchmeyr W, Schreiber W Huber K, Rainer M, Bauer P, Tragl KH. 2002. Vienna Transdanube Aging 'VITA': Study design, recruitment strategies and level of participation. J Neural Transm Suppl 105/116.

Frank RA, Galasko D, Hampel H, Hardy J, de Leon MJ, Mehta PD, Rogers J, Siemers E, Trojanowski JQ. 2003. Biological markers for therapeutic trials in Alzheimer's disease. Proceedings of the Biological Markers Working Group; NIA initiative on neuroimaging in Alzheimer's disease. Neurobiol Aging 24:521/536.

Frears ER, Stephens DJ, Walters CE, Davies H, Austen BM. 1999. The role of cholesterol in the biosynthesis of b-amyloid. Neuroreport 10:1699/1705.

Galasko D, Chang L, Motter R, Clark CM, Kaye J, Knopman D, Thomas R, Kholodenko D, Schenk D, Lieberburg I, Miller B, Green R, Basherad R, Kertiles L, Boss MA, Seubert P. 1998.

High cerebrospinal fluid tau and low amyloid b42 levels in the clinical diagnosis of Alzheimer disease and relation to apolipoprotein E genotype. Arch Neurol 55:937/945.

Golombowski S, Muller-Spahn F, Romig H, Mendla K, Hock C. 1997. Dependence of cerebrospinal fluid Tau protein levels on apolipoprotein E4 allele frequency in patients with Alzheimer's disease. Neurosci Lett 225:213/215.

Gottfries CG, Adolfsson R, Aquilonius SM, Carlsson A, Eckernas SA Nordberg A, Oreland L, Svennerholm L, Wiberg A, Winblad B. 1983. Biochemical changes in dementia disorders of Alzheimer type (AD/ SDAT). Neurobiol Aging 4:261/271.

Go" tz ME, Fischer P, Gsell W, Riederer P, Streifler M, Simanyi M, Muller F Danielczyk W. 1998. Platelet monoamine oxidase B activity in dementia. A 4-year follow-up. Dement Geriatr Cogn Disord 9:74/77.

Greenawalt JW, Schnaitman C. 1970. An appraisal of the use of monoamine oxidase as an enzyme marker for the outer membrane of rat liver mitochondria. J Cell Biol 46:173/179.

Grundke-lqbal I, Iqbal K, Tung YC, Quinlan M, Wisniewski HM, Binder LI. 1986. Abnormal phosphorylation of the microtubule-associated protein tau (tau) in Alzheimer cytoskeletal pathology. Proc Natl Acad Sci USA 83:4913/4917.

Hampel H, Buerger K, Kohnken R, Teipel SJ, Zinkowski R, Moeller HJ, Rapoport SI, Davies P. 2001. Tracking of Alzheimer's disease progression with cerebrospinal fluid tau protein phosphorylated at threonine 231. Ann Neurol 49:545/546.

Hampel H, Buerger K, Zinkowski R, Teipel SJ, Goernitz A, Andreasen N, Sjoegren M, DeBernardis J, Kerkman D, Ishiguro K, Ohno H, Vanmechelen E, Vanderstichele H, McCulloch C, Moller HJ, Davies P, Blennow K. 2004. Measurement of phosphorylated tau epitopes in the differential diagnosis of Alzheimer disease: A comparative cerebrospinal fluid study. Arch Gen Psychiatry 61:95/102.

Harada A, Oguchi K, Okabe S, Kuno J, Terada S, Ohshima T, Sato-Yoshitake R, Takei Y, Noda T, Hirokawa N. 1994. Altered microtubule organization in small-calibre axons of mice lacking tau protein. Nature 369:488/491.

Harper JD, Lansbury PT. Jr. 1997. Models of amyloid seeding in Alzheimer's disease and scrapie: Mechanistic truths and physiological consequences of the time-dependent solubility of amyloid proteins. Annu Rev Biochem 66:385/407. 
Hesse C, Rosengren L, Andreasen N, Davidsson P, Vanderstichele H, Vanmechelen E, Blennow K. 2001. Transient increase in total tau but not phospho-tau in human cerebrospinal fluid after acute stroke. Neurosci Lett 297:187/190.

Hu YY, He SS, Wang X, Duan QH, Grundke-Iqbal I, Iqbal K, Wang J. 2002. Levels of nonphosphorylated and phosphorylated tau in cerebrospinal fluid of Alzheimer's disease patients: An ultrasensitive bienzymesubstrate-recycle enzyme-linked immunosorbent assay. Am J Pathol $160: 1269 / 1278$.

Hulstaert F, Blennow K, Ivanoiu A, Schoonderwaldt HC, Riemenschneider M, De Deyn PP, Bancher C, Cras P, Wiltfang J, Mehta PD, Iqbal K, Pottel H, Vanmechelen E, Vanderstichele H. 1999. Improved discrimination of $A D$ patients using b-amyloid(1-42) and tau levels in CSF. Neurology $52: 1555 / 1562$.

Iqbal K, Grundke-Iqbal I, Zaidi T, Merz PA, Wen GY, Shaikh SS, Wisniewski HM, Alafuzoff I, Winblad B. 1986. Defective brain microtubule assembly in Alzheimer's disease. Lancet ii:421/426.

Iqbal K, Alonso Adel C, El-Akkad E, Gong CX, Haque N, Khatoon S, Pei JJ, Tsujio I, Wang JZ, Grundke-Iqbal I. 2002. Significance and mechanism of Alzheimer neurofibrillary degeneration and therapeutic targets to inhibit this lesion. J Mol Neurosci 19:95/99.

Itoh N, Arai H, Urakami K, Ishiguro K, Ohno H, Hampel H, Buerger K, Wiltfang J, Otto M, Kretzschmar H, Moeller HJ, Imagawa M, Kohno H, Nakashima K, Kuzuhara S, Sasaki H, Imahori K. 2001. Large-scale, multicenter study of cerebrospinal fluid tau protein phosphorylated at serine 199 for the antemortem diagnosis of Alzheimer's disease. Ann Neurol 50:150/156.

Jossan SS, Gillberg PG, Gottfries CG, Karlsson I, Oreland L. 1991. Monoamine oxidase $B$ in brains from patients with Alzheimer's disease: A biochemical and autoradiographical study. Neuroscience 45:1/12.

Kanai M, Matsubara E, Isoe K, Urakami K, Nakashima K, Arai H, Sasaki H, Abe K, Iwatsubo T, Kosaka T, Watanabe M, Tomidokoro Y, Shizuka M, Mizushima K, Nakamura T, Igeta Y, Ikeda Y, Amari M, Kawarabayashi T, Ishiguro K, Harigaya Y, Wakabayashi K, Okamoto K, Hirai S, Shoji M. 1998. Longitudinal study of cerebrospinal fluid levels of tau, A beta140, and A beta1-42(43) in Alzheimer's disease: A study in Japan. Ann Neurol 44:17/26.

Kang J, Lemaire HG, Unterbeck A, Salbaum JM, Masters CL, Grzeschik KH, Multhaup G, Beyreuther K, Muller-Hill B. 1987. The precursor of Alzheimer's disease amyloid A4 protein resembles a cell-surface receptor. Nature 325:733/736.

Karp NA, Kreil DP, Lilley KS. 2004. Determining a significant change in protein expression with DeCyder during a pair-wise comparison using twodimensional difference gel electrophoresis. Proteomics 4:1421/1432.

Kennard ML, Feldman H, Yamada T, Jefferies WA. 1996. Serum levels of the iron binding protein $\mathrm{p} 97$ are elevated in Alzheimer's disease. Nat Med 2:1230/1235.

Knopman D. 2001. Pharmacotheraphy for Alzheimer's disease. Curr Neurol Neurosci Rep 1:428/434.

Knopman DS, DeKosky ST, Cummings JL, Chui H, Corey-Bloom J, Relkin N, Small GW, Miller B, Stevens JC. 2001. Practice parameter: diagnosis of dementia (an evidence-based review). Report of the Quality Standards Subcommittee of the American Academy of Neurology. Neurology 56:1143/1153.

Knops J, Kosik KS, Lee G, Pardee JD, Cohen-Gould L, McConlogue L. 1991. Overexpression of tau in a nonneuronal cell induces long cellular processes. J Cell Biol 114:725/733.

Lewczuk P, Esselmann H, Meyer M, Wollscheid V, Neumann M, Otto M, Maler JM, Ru"ther E, Kornhuber J, Wiltfang J. 2003. The amyloid-b (Ab) peptide pattern in cerebrospinal fluid in Alzheimer's disease: evidence of a novel carboxyterminally elongated Ab peptide. Rapid Commun Mass Spectrom 17:1291/1296.

Lewczuk P, Esselmann H, Bibl M, Beck G, Maler JM, Otto M, Kornhuber J, Wiltfang J. 2004a. Tau protein phosphorylated at threonine 181 in CSF as a neurochemical biomarker in Alzheimer's disease: Original data and review of the literature. $\mathrm{J} \mathrm{Mol} \mathrm{Neurosci} \mathrm{23:115/122.}$

Lewczuk P, Esselmann H, Groemer TW, Bibl M, Maler JM, Steinacker P, Otto M, Kornhuber J, Wiltfang J. 2004b. Amyloid b peptides in cerebrospinal fluid as profiled with surface enhanced laser desorption/ionization time-of-flight mass spectrometry: Evidence of novel biomarkers in Alzheimer's disease. Biol Psychiatry 55:524/530.
Lewczuk P, Esselmann H, Otto M, Maler JM, Henkel AW, Henkel MK, Eikenberg 0, Antz C, Krause WR, Reulbach U, Kornhuber J, Wiltfang J. 2004c. Neurochemical diagnosis of Alzheimer's dementia by CSF Ab42, Ab42/Ab40 ratio and total tau. Neurobiol Aging 25:273/281.

Lewczuk P, Esselmann H, Bibl M, Paul S, Svitek J, Miertschischk J, Meyrer R, Smirnov A, Maler J.M, Klein C, Otto M, Bleich S, Sperling W, Kornhuber $\mathrm{J}, \mathrm{Ru}$ "ther E, Wiltfang J. 2004d. Electrophoretic separation of amyloid b (Ab) peptides in plasma. Electrophoresis 25:3336/3343.

Louis ED, Lynch T, Kaufmann P, Fahn S, Odel J. 1996. Diagnostic guidelines in central nervous system Whipple's disease. Ann Neurol 40:561/568.

Louis ED. 2003. Whipple disease. Curr Neurol Neurosci Rep 3:470/475.

Luer W, Poser S, Weber T, Jurgens S, Eichenlaub D, Pohle HD, Felgenhauer K. 1988. Chronic HIV encephalitis. I. Cerebrospinal fluid diagnosis. Klin Wochenschr 66:21/25.

Mawal-Dewan M, Henley J, Van de Voorde A, Trojanowski JQ, Lee VM. 1994. The phosphorylation state of tau in the developing rat brain is regulated by phosphoprotein phosphatases. J Biol Chem 269:30981/30987.

Mayeux R. 1998. Evaluation and use of diagnostic tests in Alzheimer's disease. Neurobiol Aging 19:139/143.

Mayeux R, Saunders AM, Shea S, Mirra S, Evans D, Roses AD, Hyman BT, Crain B, Tang MX, Phelps CH. 1998. Utility of the apolipoprotein E genotype in the diagnosis of Alzheimer's disease. Alzheimer's Disease Centers Consortium on Apolipoprotein E and Alzheimer's Disease. New Engl J Med 338:506/511.

McGeer PL, McGeer EG. 2001. Inflammation, autotoxicity and Alzheimer disease. Neurobiol Aging 22:799/809.

Merchant M, Weinberger SR. 2000. Recent advancements in surfaceenhanced laser desorption/ionization-time of flightmass spectrometry. Electrophoresis 21:1164/1177.

Motter R, Vigo-Pelfrey C, Kholodenko D, Barbour R, Johnson-Wood K, Galasko D, Chang L, Miller B, Clark C, Green R et al. 1995. Reduction of beta-amyloid peptide42 in the cerebrospinal fluid of patients with Alzheimer's disease. Ann Neurol 38:643/648.

Mulder C, Scheltens P, Visser JJ, van Kamp GJ, Schutgens RB. 2000. Genetic and biochemical markers for Alzheimer's disease: Recent developments. Ann Clin Biochem 37:593/607.

Na"gga K, Gottfries J, Blennow K, Marcusson J. 2002. Cerebrospinal fluid phospho-tau, total tau and b-amyloid1-42 in the differentiation between Alzheimer's disease and vascular dementia. Dement Geriatr Cogn Disord 14:183/190.

Nakamura S, Kawamata T, Akiguchi I, Kameyama M, Nakamura N, Kimura H. 1990. Expression of monoamine oxidase B activity in astrocytes of senile plaques. Acta Neuropathol (Berlin) 80:419/425.

National Institute on Aging Working Group. 1998. Consensus report of the Working Group on: 'Molecular and Biochemical Markers of Alzheimer's Disease'. The Ronald and Nancy Reagan Research Institute of the Alzheimer's Association and the National Institute on Aging Working Group. Neurobiol Aging 19:109/116.

Navia BA, Price RW. 1987. The acquired immunodeficiency syndrome dementia complex as the presenting or sole manifestation of human immunodeficiency virus infection. Arch Neurol 44:65/69.

Oreland L, Gottfries CG. 1986. Brain and brain monoamine oxidase in aging and in dementia of Alzheimer's type. Prog Neuropsychopharmacol Biol Psychiatry 10:533/540.

Otto M, Wiltfang J, Tumani H, Zerr I, Lantsch M, Kornhuber J, Weber T, Kretzschmar HA, Poser S. 1997. Elevated levels of tau-protein in cerebrospinal fluid of patients with Creutzfeldt-Jakob disease. Neurosci Lett 225:210/212.

Otto M, Esselmann H, Schulz-ShaefferW, Neumann M, Schroter A, Ratzka P, Cepek L, Zerr I, Steinacker P, WindI O, Kornhuber J, Kretzschmar HA, Poser S, Wiltfang J. 2000.

Decreased b-amyloid1-42 in cerebrospinal fluid of patients with CreutzfeldtJakob disease. Neurology 54:1099/1102.

Panegyres PK. 1997. The amyloid precursor protein gene: A neuropeptide gene with diverse functions in the central nervous system. Neuropeptides 31:523/535.

Papassotiropoulos A, Streffer JR, Tsolaki M, Schmid S, Thal D, Nicosia F, lakovidou V, Maddalena A, Lütjohann D, Ghebremedhin E, Hegi T, Pasch T, Tra"xler M, Bru“ hl A, Benussi L, Binetti G, Braak H, Nitsch R.M, Hock C. 2003. Increased brain b-amyloid load, phosphorylated 
tau, and risk of Alzheimer disease associated with an intronic CYP46 polymorphism. Arch Neurol 60:29/35.

Parnetti L, Reboldi GP, Santucci C, Santucci A, Gaiti A, Brunetti M, Cecchetti R, Senin U. 1994. Platelet MAO-B activity as a marker of behavioural characteristics in dementia disorders. Aging (Milano) 6:201/207.

Parnetti L, Lanari A, Amici S, Gallai V, Vanmechelen E, Hulstaert F. 2001. CSF phosphorylated tau is a possible marker for discriminating Alzheimer's disease from dementia with Lewy bodies., Phospho-Tau International Study Group. Neurol Sci 22:77/78.

Petersen RC, Smith GE, Waring SC, Ivnik RJ, Tangalos EG, Kokmen E. 1999. Mild cognitive impairment: clinical characterization and outcome. Arch Neurol 56:303/308.

Pitschke M, Prior R, Haupt M, Riesner D. 1998. Detection of single amyloid beta-protein aggregates in the cerebrospinal fluid of Alzheimer's patients by fluorescence correlation spectroscopy. Nat Med 4:832/834.

Poser S, Luer W, Eichenlaub D, Pohle HD, Weber T, Jurgens S, Felgenhauer K. 1988. Chronic HIV encephalitis. II. Clinical aspects. Klin Wochenschr $66: 26 / 31$.

Pratico D, Uryu K, Leight S, Trojanoswki JQ, Lee VM. 2001. Increased lipid peroxidation precedes amyloid plaque formation in an animal model of Alzheimer amyloidosis. J Neurosci 21:4183/4187.

Pratico D, Clark CM, Liun F, Rokach J, Lee VY, Trojanowski JQ. 2002. Increase of brain oxidative stress in mild cognitive impairment: A possible predictor of Alzheimer disease. Arch Neurol 59:972/976.

Quality Standards Subcommittee of the American Academy of Neurology. 1994. Practice parameter for diagnosis and evaluation of dementia (summary statement). Report of the Quality Standards Subcommittee of the American Academy of Neurology. Neurology 44:2203/2206.

Rao SM. 1986. Neuropsychology of multiple sclerosis: A critical review. J Clin Exp Neuropsychol 8:503/542.

Reiber H, Ungefehr S, Jacobi C. 1998. The intrathecal, polyspecific and oligoclonal immune response in multiple sclerosis. Mult Scler 4:111/117.

Reiber H. 2001. Dynamics of brain-derived proteins in cerebrospinal fluid. Clin Chim Acta 310:173/186.

Reiber H, Peter JB. 2001. Cerebrospinal fluid analysis: Disease related data patterns and evaluation programs. J Neurol Sci 184:101/122.

Riederer P, Youdim MBH. 1993. The therapeutic place and value of present and future MAO-B inhibitors-L-deprenyl as the gold standard. In: Szelenyi J, editor. Inhibitors of monoamine oxidase B, pharmacology and clinical use in neurodegenerative disorders. Basel: Birkha"user. p 327/338.

Riemenschneider M, Schmolke M, Lautenschlager N, Guder WG, Vanderstichele H, Vanmechelen E, Kurz A. 2000. Cerebrospinal beta-amyloid (1-42) in early Alzheimer's disease: Association with apolipoprotein $\mathrm{E}$ genotype and cognitive decline. Neurosci Lett 284:85/88.

Rosner H, Rebhan M, Vacun G, Vanmechelen E. 1995. Developmental expression of tau proteins in the chicken and rat brain: Rapid downregulation of a paired helical filament epitope in the rat cerebral cortex coincides with the transition from immature to adult tau isoforms. Int J Dev Neurosci 13:607/617.

Rovaris M, Filippi M. 2000. MRI correlates of cognitive dysfunction in multiple sclerosis patients. J Neurovirol 6 (Suppl 2):S172/175.

Saura J, Luque JM, Cesura AM, Da Prada M, Chan-Palay V, Huber G, Loffler J, Richards JG. 1994. Increased monoamine oxidase B activity in plaque-associated astrocytes of Alzheimer brains revealed by quantitative enzyme radioautography. Neuroscience 62:15/30.

Schoonenboom NS, Pijnenburg YA, Mulder C, Rosso SM, Van Elk EJ, Van Kamp GJ, Van Swieten JC, Scheltens P. 2004. Amyloid beta(1/42) and phosphorylated tau in CSF as markers for early-onset Alzheimer disease. Neurology 62:1580/1584.

Selkoe DJ. 1994. Cell biology of the amyloid beta-protein precursor and the mechanism of Alzheimer's disease. Annu Rev Cell Biol 10:373/403.

Sengupta A, Kabat J, Novak M, Wu Q, Grundke-Iqbal I, Iqbal K. 1998. Phosphorylation of tau at both Thr 231 and Ser 262 is required for maximal inhibition of its binding to microtubules. Arch Biochem Biophys $357: 299 / 309$

Seshadri S, Beiser A, Selhub J, Jacques PF, Rosenberg IH, D'Agostino RB, Wilson PW, Wolf PA. 2002. Plasma homocysteine as a risk factor for dementia and Alzheimer's disease. New Engl J Med 346:476/483.

Shahani N, Brandt R. 2002. Functions and malfunctions of the tau proteins. Cell Mol Life Sci 59:1668/1680.
Singh TJ, Wang JZ, Novak M, Kontzekova E, Grundke-Iqbal I, Iqbal K. 1996. Calcium/calmodulin-dependent protein kinase II phosphorylates tau at Ser-262 but only partially inhibits its binding to microtubules. FEBS Lett 387:145/148.

Sjogren M, Vanderstichele H, Agren H, Zachrisson O, Edsbagge M, Wikkelso C, Skoog I, Wallin A, Wahlund LO, Marcusson J, Nagga K, Andreasen $\mathrm{N}$, Davidsson P, Vanmechelen E, Blennow K. 2001. Tau and Abeta42 in cerebrospinal fluid from healthy adults 21/93 years of age: Establishment of reference values. Clin Chem 47:1776/1781.

Sjo"gren M, Gisslen M, Vanmechelen E, Blennow K. 2001. Low cerebrospinal fluid b-amyloid 42 in patients with acute bacterial meningitis and normalization after treatment. Neurosci Lett 314:33/36.

Smith RC, Ho BT, Kralik P, Vroulis G, Gordon J, Wolff J. 1982. Platelet monamine oxidase in Alzheimer's disease. J Gerontol 37:572/574.

Song W, Zhou LJ, Zheng SX, Zhu XZ. 2000. Amyloid-beta 25/35 peptide induces expression of monoamine oxidase $B$ in cultured rat astrocytes. Acta Pharmacol Sin 21:557/563.

Sparks DL, Woeltz VM, Markesbery WR. 1991. Alterations in brain monoamine oxidase activity in aging, Alzheimer's disease, and Pick's disease. Arch Neurol 48:718/721.

Stamer K, Vogel R, Thies E, Mandelkow E, Mandelkow EM. 2002. Tau blocks traffic of organelles, neurofilaments, and APP vesicles in neurons and enhances oxidative stress. J Cell Biol 156:1051/1063.

Strittmatter WJ, Saunders AM, Schmechel D, Pericak-Vance M, Enghild J, Salvesen GS, Roses AD. 1993a. Apolipoprotein E: high-avidity binding to beta-amyloid and increased frequency of type 4 allele in late-onset familial Alzheimer disease. Proc Natl Acad Sci USA 90:1977/1981.

Strittmatter WJ, Weisgraber KH, Huang DY, Dong LM, Salvesen GS, PericakVance M, Schmechel D, Saunders AM, Goldgaber D, Roses AD. 1993b. Binding of human apolipoprotein $E$ to synthetic amyloid beta peptide: Isoform-specific effects and implications for late-onset Alzheimer disease. Proc Natl Acad Sci USA 90:8098/8102.

Sunderland T, Linker G, Mirza N, Putnam KT, Friedman DL, Kimmel LH, Bergeson J, Manetti GJ, Zimmermann M, Tang B, Bartko JJ, Cohen RM. 2003. Decreased beta-amyloid1/42 and increased tau levels in cerebrospinal fluid of patients with Alzheimer disease. J Am Med Assoc 289:2094/2103.

Takei Y, Teng J, Harada A, Hirokawa N. 2000. Defects in axonal elongation and neuronal migration in mice with disrupted tau and map1b genes. J Cell Biol 150:989/1000.

Tarkowski E, Issa R, Sjogren M, Wallin A, Blennow K, Tarkowski A, Kumar P. 2002. Increased intrathecal levels of the angiogenic factors VEGF and TGF-beta in Alzheimer's disease and vascular dementia. Neurobiol Aging 23:237/243.

Tatebayashi Y, Haque N, Tung YC, Iqbal K, Grundke-Iqbal I. 2004. Role of tau phosphorylation by glycogen synthase kinase-3beta in the regulation of organelle transport. J Cell Sci 117:1653/1663.

Tumani H, Nolker G, Reiber H. 1995. Relevance of cerebrospinal fluid variables for early diagnosis of neuroborreliosis. Neurology 45:1663/1670.

Ujiie M, Dickstein DL, JefferiesWA. 2002. p97 as a biomarker for Alzheimer disease. Front Biosci 7:E42/47.

Vanmechelen E, Vanderstichele H, Davidsson P, Van Kerschaver E, Van Der Perre B, Sjo"gren M, Andreasen N, Blennow K. 2000. Quantification of tau phosphorylated at threonine 181 in human cerebrospinal fluid: $\mathrm{A}$ sandwich ELISA with a synthetic phosphopeptide for standardization. Neurosci Lett 285:49/52.

Vanmechelen E, Van Kerschaver E, Blennow K, De Deyn PP, Galasko D, Parnetti L, Sindic CJM, Arai H, Riemenschneider M, Hampel H, Pottel H, Valgaeren A, Hulstaert F, Vanderstichele H. 2001. CSF-Phospho-tau (181P) as a promising marker for discriminating Alzheimer's disease from dementia with Lewy bodies in Alzheimer's disease. In: Iqbal K, Sisodia SS, Winblad B, editors. Advances in etiology, pathogenesis and therapeutics. Chichester: John Wiley and Sons Ltd. p 285/291.

Vignali DA. 2000. Multiplexed particle-based flow cytometric assays. J Immunol Methods 243:243/255.

Weyler W, Hsu YP, Breakefield XO. 1990. Biochemistry and genetics of monoamine oxidase. Pharmacol Ther 47:391/417.

Wiltfang J, Arold N, Neuhoff V. 1991. A new multiphasic buffer system for sodium dodecyl sulfate-polyacrylamide gel electro-phoresis of proteins and peptides with molecular masses 100,000/1000, and their detection with picomolar sensitivity. Electrophoresis 12:352/366. 
Wiltfang J, Esselmann H, Cupers P, Neumann M, Kretzschmar H, Beyermann M, Schleuder D, Jahn H, Ru" ther E, Kornhuber J, Annaert W, De Strooper B, Saftig P. 2001a. Elevation of b-amyloid peptide 2-42 in sporadic and familial Alzheimer's disease and its generation in PS1 knockout cells. J Biol Chem 276:42645/42657.

Wiltfang J, Esselmann H, Maler JM, Bleich S, Hu" ther G, Kornhuber J. 2001b. Molecular biology of Alzheimer's dementia and its clinical relevance to early diagnosis and new therapeutic strategies. Gerontology 47:65/71.

Wiltfang J, Esselmann H, Bibl M, Smirnov A, Otto M, Paul S, Schmidt B, Klafki HW, Maler M, Dyrks T, Bienert M, Beyermann M, Ru" ther E, Kornhuber J. 2002. Highly conserved and disease-specific patterns of carboxyterminally truncated $\mathrm{Ab}$ peptides $1 / 37 / 38 / 39$ in addition to $1 / 40 / 42$ in Alzheimer's disease and in patients with chronic neuroinflammation. J Neurochem 81:481/496.

Zetterberg H, Wahlund LO, Blennow K. 2003. Cerebrospinal fluid markers for prediction of Alzheimer's disease. Neurosci Lett 352:67/69.

Zetterberg H, Andreasen N, Blennow K. 2004. Increased cerebrospinal fluid levels of transforming growth factor-beta1 in Alzheimer's disease. Neurosci Lett 367:194/196.

Zhou G, Miura Y, Shoji H, Yamada S, Matsuishi T. 2001. Platelet monoamine oxidase B and plasma beta-phenylethylamine in Parkinson's disease. J Neurol Neurosurg Psychiatry 70:229/231. 